\title{
Large Decadal Decline of the Arctic Multiyear Ice Cover
}

\author{
JOSEFINO C. COMISO \\ Cryospheric Sciences Branch, NASA Goddard Space Flight Center, Greenbelt, Maryland
}

(Manuscript received 19 February 2011, in final form 26 July 2011)

\begin{abstract}
The perennial ice area was drastically reduced to $38 \%$ of its climatological average in 2007 but recovered slightly in 2008, 2009, and 2010 with the areas being $10 \%, 24 \%$, and $11 \%$ higher than in 2007 , respectively. However, trends in extent and area remained strongly negative at $-12.2 \%$ and $-13.5 \%$ decade $^{-1}$, respectively. The thick component of the perennial ice, called multiyear ice, as detected by satellite data during the winters of 1979-2011 was studied, and results reveal that the multiyear ice extent and area are declining at an even more rapid rate of $-15.1 \%$ and $-17.2 \%$ decade $^{-1}$, respectively, with a record low value in 2008 followed by higher values in 2009, 2010, and 2011. Such a high rate in the decline of the thick component of the Arctic ice cover means a reduction in the average ice thickness and an even more vulnerable perennial ice cover. The decline of the multiyear ice area from 2007 to 2008 was not as strong as that of the perennial ice area from 2006 to 2007, suggesting a strong role of second-year ice melt in the latter. The sea ice cover is shown to be strongly correlated with surface temperature, which is increasing at about 3 times the global average in the Arctic but appears weakly correlated with the Arctic Oscillation (AO), which controls the atmospheric circulation in the region. An 8-9-yr cycle is apparent in the multiyear ice record, which could explain, in part, the slight recovery in the last $3 \mathrm{yr}$.
\end{abstract}

\section{Introduction}

The most visible change in the Arctic region in recent years has been the rapid decline of the perennial ice cover, as previously reported by Comiso (2002). The perennial ice has been defined as the ice that survives the summer and represents the thick component of the sea ice cover that may include ridged first-year ice (FYI). A drastic retreat of summer sea ice in the Beaufort Sea in 1998 was followed by record lows in the perennial ice cover in 2002 and in 2005. However, there was none more dramatic than in 2007 when the area of the perennial ice was reduced to about $37 \%$ of the climatological average value and $28 \%$ of the previous low value in 2005 (Comiso et al. 2008). Such a drastic change in the perennial ice cover has been the subject of several studies (e.g., Simmonds et al. 2008; Perovich et al. 2008) and has been regarded as the event that could trigger an irreversible change in the Arctic sea ice cover (Lindsay et al. 2009; Serreze 2009; Amstrup et al. 2010), while others argue that an anomaly during a single

Corresponding author address: Josefino C. Comiso, Cryospheric Sciences Branch, NASA Goddard Space Flight Center, Code 614.1, Greenbelt, MD 20771.

E-mail: josefino.c.comiso@nasa.gov summer can be reversible through a recovery mechanism (Tietsche et al. 2011). The temperature of the upper layer of the Arctic Ocean is expected to have been increasing because of more solar heat absorbed by more extensive ice-free areas in the summer in recent years. The temperature may have already increased to a level that makes it difficult for sea ice to grow thick enough in winter and spring to be able to survive the summer melt period. The ice decline in 2007 has been attributed to the simultaneous occurrences of a number of phenomena including icealbedo feedback (J. Zhang et al. 2008; Perovich et al. 2008), surface temperature (Steele et al. 2008; Shibata et al. 2010), winds and ice motion (Ogi et al. 2008; Kwok 2008), increased cyclone activities (Simmonds et al. 2008), and an unusual cloud-free condition (Kay et al. 2008; Schweiger et al. 2008). The observed trends in the ice cover is even more negative than those predicted by modeling studies (Stroeve et al. 2007), suggesting that the impacts of greenhouse warming in the Arctic may be stronger than has been projected. The possible influence of ENSO on the Arctic sea ice cover has been reported (Liu et al. 2004) for previous episodes but not studied for the 2007 decline.

The dramatic decline of the perennial ice cover in 2007 was followed by a slight recovery for three consecutive years. Such recovery is intriguing and obviously needs to 
be better understood. Part of the recovery may be attributed to a global cooling that has been associated with the La Niña of 2008, the impact of which extended as far south as Antarctica where the sea ice extent in the region attained record high values in 2008. To gain insights into this phenomenon, we study the changes in the multiyear ice cover, as derived from passive microwave data during the winter months, over the same 1978-2011 period. Similar studies of the changes in the multiyear ice cover have been performed using active sensors like the Quick Scatterometer (QuikSCAT; Nghiem et al. 2007; Kwok and Rothrock 2009) but the passive microwave data provide a more robust dataset because of the availability of more than two channels that are used to reduce the ambiguity in discriminating multiyear ice, first-year, ice and ice-free water, and because of a considerably longer record length (32 versus $12 \mathrm{yr}$ ). Multiyear ice, or ice that has survived at least two summers, as defined by the World Meteorological Organization (WMO), is the thick component of the perennial ice cover, which also includes second-year ice or ice that has survived only one summer and some ridged first-year ice. The time series of the multiyear ice data is used to assess interannual changes and decadal trends of the extent and area of this thicker component of the sea ice cover. Such changes and trends are in turn examined in conjunction with observed changes in surface temperature, winds, and sea level pressure to evaluate the strength of the relationships of these variables. Analysis of the data also provides the means to quantify the spatial changes in the distribution and drift patterns of multiyear ice floes in autumn and winter.

\section{Current state of the Arctic sea ice cover}

The Arctic sea ice cover is known to be highly seasonal with the ice extent changing from about $6 \times 10^{6} \mathrm{~km}^{2}$ in the summer to about $15 \times 10^{6} \mathrm{~km}^{2}$ in the winter (Comiso 2010). These interannual changes are also known to be different for the different seasons, with the interannual trends in winter being more moderate than those in the summer. The pan-Arctic sea ice cover has undergone significant changes from November 1978 to December 2010 as depicted by the sea ice extent monthly anomalies presented in Fig. 1a. The plot shows large yearly fluctuations of about $1 \times 10^{6} \mathrm{~km}^{2}$ in the first $16 \mathrm{yr}$ but after the positive anomaly in 1996 the values went through a steady decline and in 2007 a dramatic decline in the ice cover at the end of summer was observed. Large seasonal variability was also observed in 2007 and subsequent years with the end of summer ice remaining relatively low in 2008, 2009, and 2010 as well. Using linear regression on monthly anomaly data from November 1978 to 2010, the trend in ice extent is estimated to be $-4.0 \% \pm 0.2 \%$ decade $^{-1}$, while for the
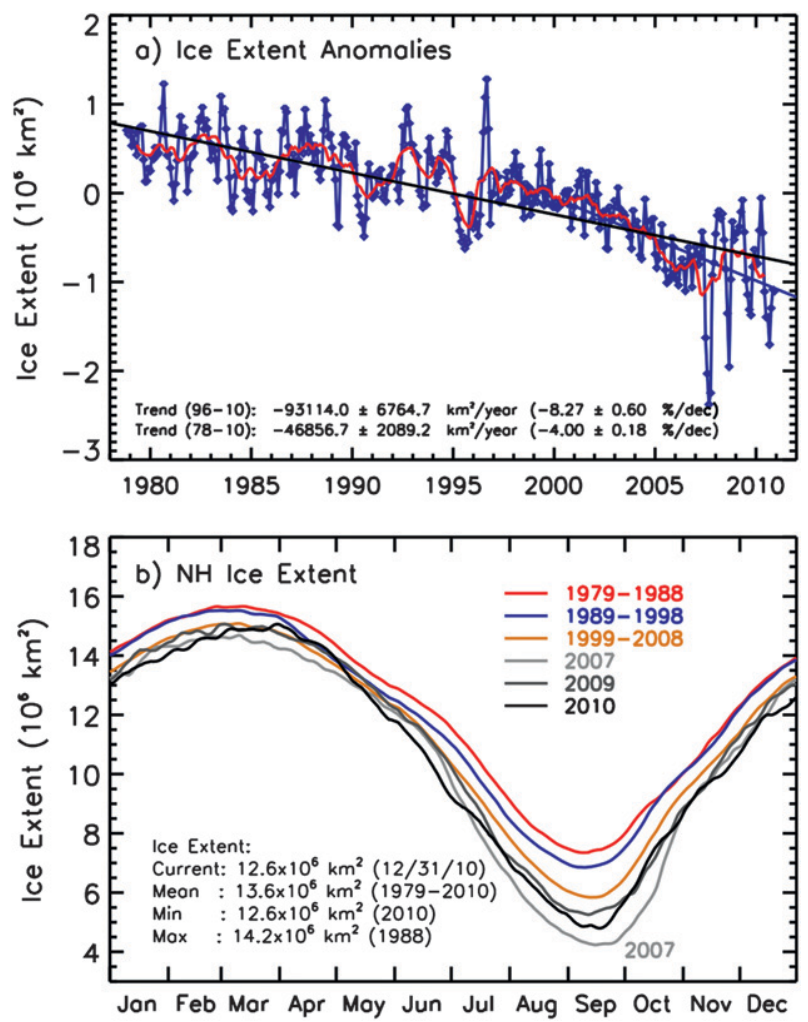

FIG. 1. (a) Monthly anomalies of the extent of the sea ice cover in the Northern Hemisphere. (b) The 10-yr averages of daily ice extents and daily ice extents in 2007, 2009, and 2010.

period 1996-2010, the trend is $-8.3 \% \pm 0.6 \%$ decade $^{-1}$. This indicates that since 1996, the Arctic sea ice cover has been declining at a rate that is more than twice the overall rate during the 1978-2010 period. Although the ice extents in the winter months of 2007, 2008, 2009, and 2010 were close to the average value during the last decade, the minimum values in September as derived from the daily averages were consistently low at $4.24,4.63,5.26$, and $4.80 \times 10^{6} \mathrm{~km}^{2}$, respectively, and represent the four lowest in the time series. These minimum values provide a measure of the extent of the perennial ice cover during these years.

Figure 1b shows how the seasonality of the Arctic sea ice cover has changed during the last three decades and the last few years. The three colored lines in the plots represent 10 -yr averages of daily data with the red line representing the first $10 \mathrm{yr}$ of data (i.e., 1979-88), the blue representing the second $10 \mathrm{yr}$ of data (i.e., 1989-98), and the gold representing the third $10 \mathrm{yr}$ of data (i.e., 1999-2008). The other lines represent data from individual years with the light gray line representing 2007, the darker gray line representing 2009, and the boldface black line representing 2010. The plots indicate that the highest extent occurs in February or March while the lowest extents occur at the 
end of the summer melt period, which happens during the month of September. In winter (e.g., January, February, or March) the change in extent from the first to the second decade was almost zero while the change from the second to the third decade was slightly more and is around $0.6 \times$ $10^{6} \mathrm{~km}^{2}$. In contrast, at the end of the summer (i.e., September), the changes are more significant with the change from the first to the second decade being around $0.5 \times$ $10^{6} \mathrm{~km}^{2}$ while that from the second to the third decade is around $1.2 \times 10^{6} \mathrm{~km}^{2}$. The changes in the Arctic ice cover are thus more pronounced in the summer than in the winter period. The changes were even more drastic in the last $4 \mathrm{yr}$ as revealed by the individual plots for the years 2007, 2009, and 2010. The data for 2008 fall between those of 2007 and 2009 and were not shown to minimize overcrowding of the lines. Figure $1 \mathrm{~b}$ also shows that the change from the first to the second decade was significant mainly in spring and summer while the change from the second to the third decade was significant in all seasons. The largest interannual changes apparently occur at the end of the summer and during the summer minimum, and the values basically represent those of the perennial ice cover as described in Comiso (2002). Note that the ice extents for each day during the last week of December 2010 were significantly lower than those in previous years and were actually the record low values during the satellite era. Low values suggest a relatively warm winter that keeps the growth rate of ice (including thickness) relatively low. The persistence of such low ice area values in winter would mean that a recovery for the perennial ice in 2011 is highly unlikely because such a retreat in the sea ice cover would mean warmer atmospheric temperatures (Screen and Simmonds 2010).

\section{Multiyear ice concentration}

Multiyear ice has been defined by the WMO as ice that has survived at least two summer periods and is the thick component of the perennial ice cover, which includes the relatively thinner second-year ice cover. This definition is different from that of other investigators (Gloersen et al. 1992; Zwally and Gloersen 2008), including some modelers, who regard perennial ice as identical to multiyear ice. The difference in the signature of multiyear ice compared with seasonal ice has been reported previously (Vant et al. 1978) and has been confirmed using satellite data (e.g., Gloersen et al. 1992; Comiso 2006; Zwally and Gloersen 2008). The passive microwave (PM) signature of multiyear ice is significantly different from that of first-year ice because of differences in salinity and, therefore, dielectric properties (Vant et al. 1978). Seasonal ice, which is also referred to as first-year ice, is relatively saline because of the presence of brine entrapped during ice formation.
On average, the surface salinity of first year ice is about 10-12 practical salinity unit ( $\mathrm{psu}$ ) while that of multiyear ice approaches 0 psu (Weeks and Ackley 1986). Saline first-year ice has a loss tangent (defined as the ratio of the imaginary and the real parts of the dielectric constant) that is relatively high, making it opaque to radiation. On the other hand, the loss tangent of desalinated multiyear ice is low, making the material transparent to radiation and vulnerable to scattering effects. The net result is high emissivity for first-year ice and relatively low emissivity for multiyear ice (Vant et al. 1978; Eppler et al. 1992) making it possible to discriminate between these two ice types. It should be noted that although the emissivity of first-year ice is relatively well defined on account of the opacity of the material, the emissivity of multiyear ice, which depends on the fraction of contaminants or scatterers in the material (i.e., on the history of the material), could vary significantly (e.g., from region to region) (Matzler et al. 1984; Grenfell 1992). Moreover, the signature of secondyear ice has been observed to be intermediate to those of first-year and multiyear ice (Tooma et al. 1975). Results of time series analyses of satellite data actually suggest that the signature of second-year ice is closer to that of firstyear ice (Comiso 2006) and overlaps with that of relatively low concentration multiyear ice. This has been further confirmed in the Antarctic region where second-year ice is practically the oldest ice type in the region (Gloersen et al. 1992) because the ice floes that survive the summer are usually advected to the north, where they melt.

The microwave brightness temperatures of sea ice and open water for different frequencies and polarizations vary considerably, as illustrated in the $3 \mathrm{D}$ scatterplots in Fig. 2a, which makes use of Advanced Microwave Scanning Radiometer for Earth Observing System (AMSR-E) 36-GHz $T_{B}$ data at horizontal and vertical polarizations and $89-\mathrm{GHz} T_{B}$ at vertical polarization. Projections of the 3D data to the 2D components are also shown in Fig. 2a with the top left being the 2D plot of $89 \mathrm{GHz}(\mathrm{V})$ versus $36 \mathrm{GHz}(\mathrm{V})$, top right for $89 \mathrm{GHz}(\mathrm{V})$ versus $36 \mathrm{GHz}(\mathrm{H})$, and the bottom plot being $36 \mathrm{GHz}$ $(\mathrm{H})$ versus $36 \mathrm{GHz}(\mathrm{V})$. The cluster of data points in the vicinity of $\mathrm{O}$ represents open water, while those near $\mathrm{A}$, C, and D represent first-year ice, second-year ice (or first-year ice with thick snow cover), and multiyear ice, respectively. A large scatter of data for the different ice types is apparent, reflecting the large variability in the emissivity of the different ice types, especially multiyear ice. The variations in emissivity are in part due to the presence of mixtures of different ice types. The emissivity is shown to be more variable at higher frequencies because of the shorter wavelengths that make the emitted radiation more vulnerable to scattering than those with longer wavelengths. 


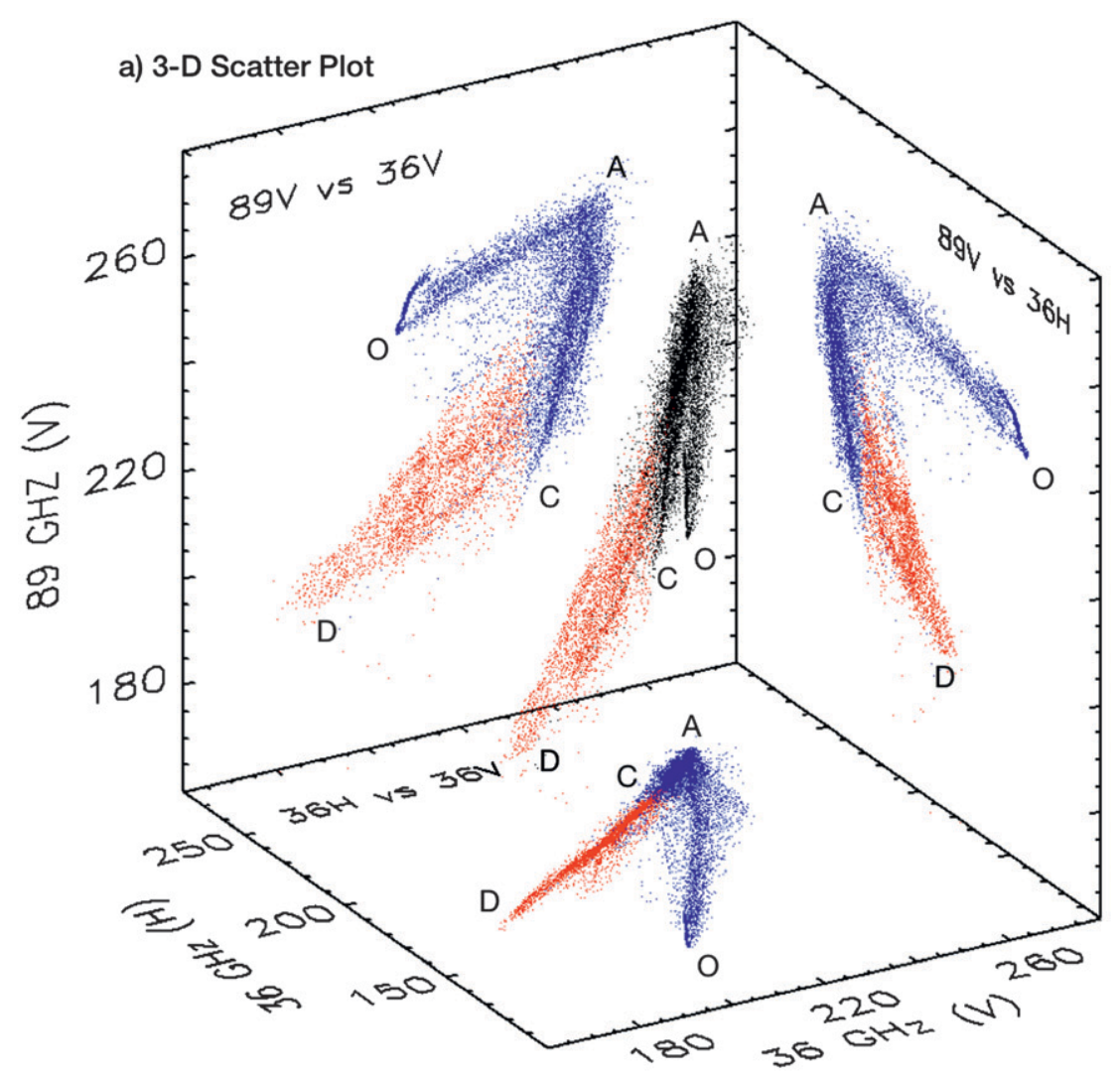

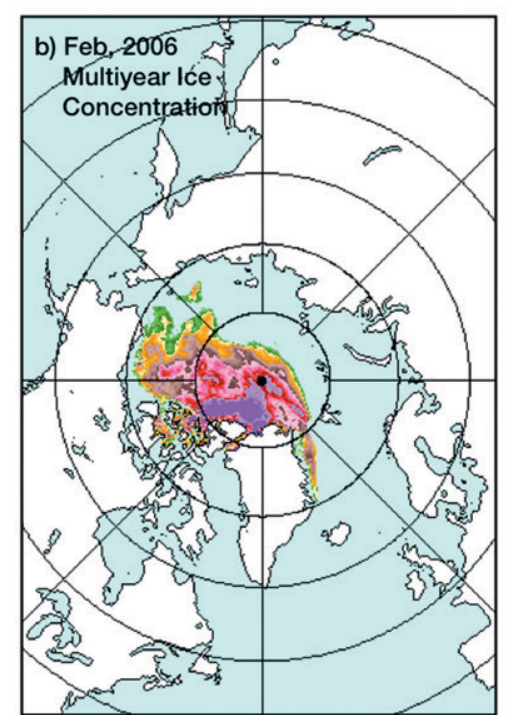

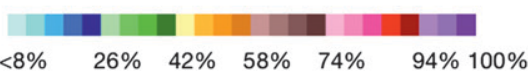

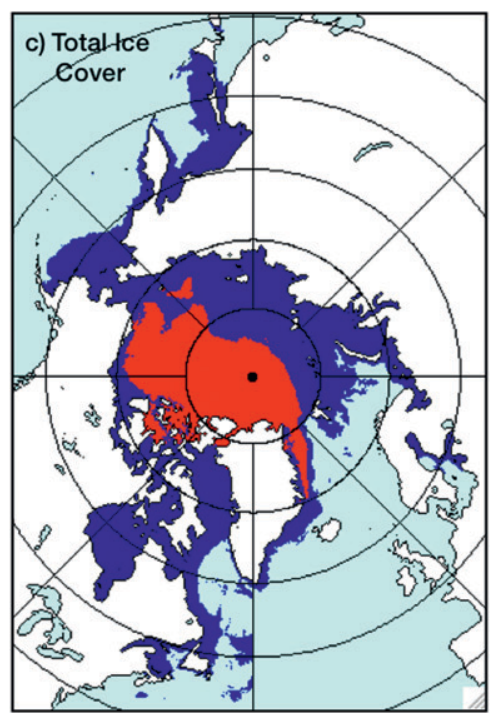

First Year Ice Multiyear Ice

FIG. 2. (a) A 3D scatterplot of $37 \mathrm{GHz}$ (V) vs $37 \mathrm{GHz}(\mathrm{H})$ vs $89 \mathrm{GHz}$ (V) using AMSR-E data. The 2D projections of each pair of channels are also shown. The data points near $\mathrm{O}, \mathrm{A}$, and $\mathrm{D}$ represent open water, first-year ice, and multiyear ice, respectively. Data points near $\mathrm{C}$ represent either second-year ice or first-year ice with thick snow cover. (b) A map of the derived multiyear ice concentration for February 2006 and (c) the winter ice cover with the location of multiyear ice with an ice concentration of $30 \%$ or more shown in red while the seasonal ice is shown in blue. In the 3D scatterplot, the data points representing multiyear ice cover with $30 \%$ ice concentration or more are also represented in red. 
Large temporal and spatial variabilities in the microwave brightness temperature of multiyear ice are apparent when scatterplots such as those shown in Fig. 2 are plotted for each month. To minimize the errors associated with this variability, a dynamic tie point for multiyear ice is used and adjustments are made to account for the observed monthly and yearly variations in the multiyear ice emissivity. To estimate the multiyear ice concentration, we assume that the average emissivity of multiyear and firstyear ice can be inferred from the data and that the data points in between the averages represent mixtures of multiyear and first-year (or second year) ice. The multiyear ice concentration is then derived using the following mixing algorithm:

$$
\begin{aligned}
T_{B}(\nu, P)= & T_{\mathrm{BFY}}(\nu, P) C_{\mathrm{FY}}+T_{\mathrm{BMY}}(\nu, P) C_{\mathrm{MY}} \\
& +T_{\mathrm{BOW}}(\nu, P) C_{\mathrm{OW}},
\end{aligned}
$$

where $T_{B}(\nu, P)$ is the brightness temperature observed by the satellite at frequency $\nu$ and polarization $P$ while $T_{\mathrm{BFY}}(\nu, P), T_{\mathrm{BMY}}(\nu, P)$, and $T_{\mathrm{BOW}}(\nu, P)$ are the inferred brightness temperature at the same frequency and polarization for $100 \%$ first-year ice, multiyear ice, and open water, respectively. Also, for each data element, only three types of surfaces are assumed and, therefore,

$$
C_{\mathrm{FY}}+C_{\mathrm{MY}}+C_{\mathrm{OW}}=1 .
$$

Using two AMSR-E channels (i.e., $36 \mathrm{GHz}$ at horizontal and vertical polarizations), in Eq. (1) we have two equations, and together with Eq. (2), we have the required three equations to estimate three unknowns including the concentration of multiyear ice. The typical brightness temperature is adjusted every month of the year to account for changes in the emissivity of the surface and the temperature of the ice. The existence of a fourth surface type (i.e., second-year ice) complicates the ability to do ice-type classification unambiguously and is part of the uncertainty in the procedure. However, we use a threshold of $30 \%$ for multiyear ice concentration to exclude most of the second-year ice types as discussed in Comiso (2006) and minimize the contamination of the multiyear ice data by other ice types. An example of a retrieved multiyear ice concentration is shown in Fig. 2b. Our ability to separate the thicker multiyear ice types from other ice types is surprisingly good, as described below.

The scatterplot in Fig. 2a is color coded such that the data elements with multiyear ice cover that is $30 \%$ and above are shown in red. The geographical location of the color-coded data is provided in Fig. $2 \mathrm{c}$ with the data elements from the multiyear-ice-covered region being shown in red while those in the seasonal regions (including second-year ice) are shown in blue. In the 3D scatterplot in Fig. 2a, the seasonal ice cover and openwater data (black data points) are confined to a plane defined by OAC. On the other hand, the multiyear ice data points are out of this plane and are clearly separate from the other data points. This phenomenon became more obvious when a slight rotation of the 3D scatterplot was made to make the cluster of points along $\mathrm{AC}$ and $\mathrm{AO}$ coincide along the same line, making the multiyear ice data points (in red) stand out as a separate cluster. It is thus apparent that the multiyear ice data points have signatures that are unambiguously distinct from the other data points. This is an unexpected but a most welcomed observation because it indicates that the retrieved multiyear ice data belong to a special type that can be discriminated from the other ice types.

The bootstrap algorithm, which has been used primarily to estimate sea ice concentration (Comiso 2010), makes use of the cluster of data points that follows a linear pattern along the line $\mathrm{AD}$ (see the $36 \mathrm{H}$ versus $36 \mathrm{~V}$ plot at the bottom of Fig. 2) to represent a near 100\% sea ice concentration. The same cluster of data points provides the means to estimate the multiyear ice concentration in winter when the Arctic basin is covered mainly by consolidated ice. We assume that the data in the AD cluster represent mixtures of seasonal and multiyear ice cover, with those near the label A representing 100\% first-year ice while those near the label D represent nearly $100 \%$ multiyear ice. Using the aforementioned mixing algorithm, the concentration of multiyear ice is estimated but instead of the "tie points" being fixed for all months and all years, as in Gloersen et al. (1992), Johannessen et al. (1999), and Zwally and Gloersen (2008), we used a dynamic reference point for $100 \%$ multiyear ice as indicated earlier. This adjustment is made based on the frequency distribution of the AD cluster and is done consistently for the monthly averages used in this study. In particular, the tie point is a data point near D (see Fig. 2a), about $1 / 10$ th of the length of the cluster DA from where the number of data points in the frequency distribution is zero or near zero. Monthly averages were used instead of daily data to minimize the short-term effects that may be associated with the occurrences of storms and other phenomena. The adjustments in tie points enabled the retrieval of consistent multiyear ice cover for each month when the surface is cold and dry (i.e., from November to April) and when the unique signature of the multiyear ice is most apparent.

Monthly multiyear ice concentration maps for January from 2005 to 2010 as derived using the aforementioned procedure are presented in Fig. 3. The images are very similar to those derived from QuikSCAT data for the same month (Nghiem et al. 2007; Kwok 2004). This is not surprising because both passive and active microwave data 

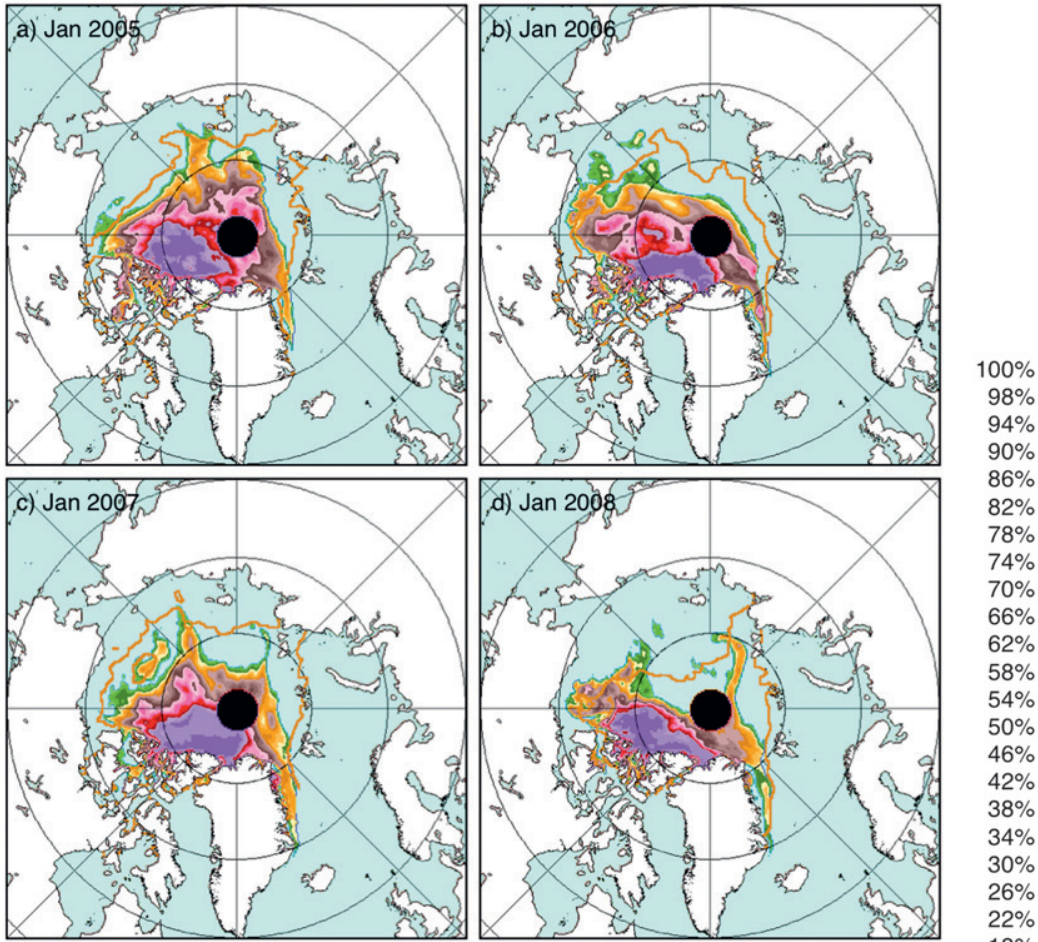

$94 \%$

$90 \%$
$86 \%$

$82 \%$

$78 \%$

$74 \%$

$70 \%$

$66 \%$

$62 \%$

$58 \%$

$54 \%$

$50 \%$

$42 \%$

$38 \%$

$34 \%$

$30 \%$

$26 \%$

$22 \%$
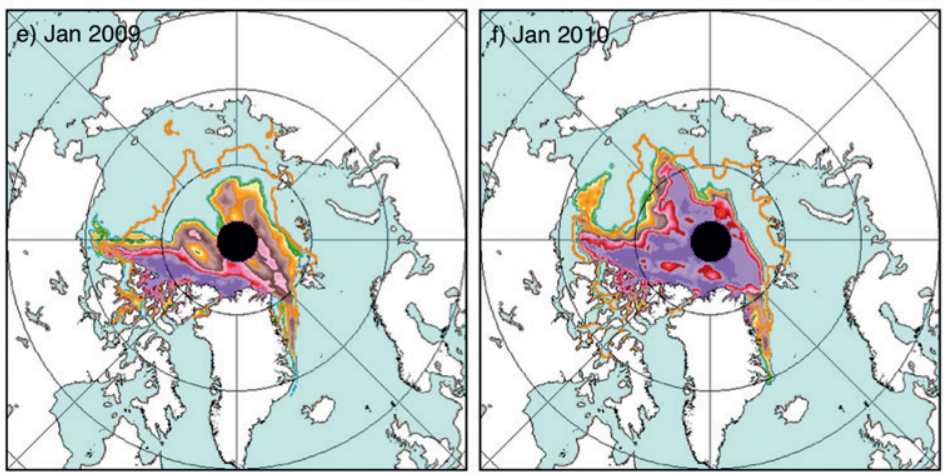

$18 \%$

$10 \%$

$8 \%$

Multiyear

Ice Concentration

Gold contours

are the perennia

ice from the

previous year.

FIG. 3. Color-coded multiyear ice concentration maps for each January from 2005 through 2010. The contour lines in gold color represent the $15 \%$ ice edge of the perennial ice cover as inferred from the sea ice cover minima the previous summer.

show a strong contrast in the signature of multiyear and first-year ice. However, there are subtle differences both at the edges and the interior that may be associated with differences in the sensitivities of the two sensors to different surface types, such as ridged ice, new ice with salt flowers, first-year ice, and open water. Multiyear ice concentrations from passive microwave data have been derived and studied previously (e.g., Gloersen et al. 1992; Walsh and Zwally 1990; Johannessen et al. 1999; Zwally and Gloersen 2008) and although the spatial features of the retrieved values are all similar, the magnitudes of the values from previous studies are generally lower because of the indicated differences in the tie points and technique. The use of a fixed tie point for multiyear ice also causes a significant but erroneous increase in the multiyear ice cover during the winter period. Such an unphysical increase is associated with changes in the emissivity due to changes in the structure and snow cover of the ice. Also, the use of a dynamic tie point allows for the adjustment needed to compensate for the expected changes in multiyear ice composition (e.g., second-year ice becomes third-year ice, etc.), which in turn causes the average emissivity of multiyear ice to be different in different years. The set of images shown in Fig. 3 illustrates how the multiyear ice cover changes from one year to another. The month with the lowest multiyear ice coverage is January 2008, which is expected because of the record low perennial ice cover in September 2007 (see contour 
line in gold). The multiyear ice cover in January 2009 (Fig. 3e) shows a more extensive coverage (by about $10 \%$ ) than does that of January 2008 but it is not as extensive as that of January 2007 (Fig. 3c). The corresponding image in January 2010 (Fig. 3f) is even more extensive (about 20\% higher than in January 2008), as can be expected because of enhanced perennial ice cover in September 2009 compared to September 2008. The increases in the multiyear extents in 2009 and in 2010 indicate that more second-year ice survived the summer melt period during these years than in 2008.

To illustrate the consistency and coherence of the derived data during the winter period and to confirm that the 2010 multiyear ice extent is reflected in other winter months, monthly multiyear ice concentration maps from November 2009 to April 2010 are presented in Fig. 4. The images in November and December are very similar but with some discrepancies near the edges that are likely associated with ice dynamics. From January to March, the unique ice formation (which looks like a tongue) near Alaska grew gradually in size. Data from this tongue in March were further analyzed (as was done in Fig. 2) and the results show that these data indeed have multiyear ice signatures. The monthly wind data that are also shown in Fig. 4 suggest that the increase in size of the tongue feature was likely caused by the advection of multiyear ice cover into the region. This is in part supported by a preliminary analysis of the ice drift data and by the results of quantitative analysis (i.e., see next section) that show that the extent and area of the multiyear ice cover did not change much from November 2009 to April 2010.

\section{Interannual variability of multiyear ice and perennial ice}

\section{a. Extent and area of multiyear and perennial ice}

Monthly multiyear ice concentrations were derived during the cold and dry months (November-April), when the multiyear ice signature is relatively stable, from 1978 to 2010. The monthly ice extent and area of multiyear ice during this period are presented in Fig. 5. The plots are color coded (as indicated) to show the value for each month during each ice season. Generally, the values show a decline during the winter season, reflecting the expected loss of multiyear ice that may be caused by the advection of the ice through the Fram Strait to the Greenland Sea and the Atlantic Ocean, where they melt. Some increases from November to December can be noted for some years and this is likely in part due to surfaces that were previously wet and did not attain their multiyear ice signature until December. It is encouraging to note, however, that the monthly changes are small when compared to the interannual variations.
It is apparent that during the 1978-2010 period the extent and area of the multiyear ice were generally declining. It is however intriguing that during the period there appears to be an 8-9-yr periodic cycle (see dash line), as is evident from 1982 to 1991, from 1991 to 2000, and from 2000 to 2008. There are some deviations from this cycle during some years, as in 1987 and 1996, but a cycle of growth and then decline is apparent over each 9-yr period. It is thus possible that the observed increase from 2008 to 2009 , and then to 2010 , is part of this periodic pattern. It is also interesting that the $8-9-y r$ cycle is also similar to the period of the Antarctic Circumpolar Wave, as described by White and Peterson (1996). This phenomenon is intriguing and deserves to be studied in detail but such study is not within the scope of this paper.

The temporal evolution of the perennial and multiyear ice cover amounts in the Arctic during the last three decades is summarized in the color-coded images presented in Fig. 6. The averages for the perennial ice for the periods 1979-88, 1989-98, and 1999-2008 are presented in Figs. $6 \mathrm{a}-\mathrm{c}$, while the corresponding averages for multiyear ice (i.e., February 1980-89, February 1990-99, and February 2000-09) are presented in Figs. 6e-g. The dates are slightly shifted since the perennial ice is observed in September of one year while the corresponding multiyear ice is observed in the subsequent winter. The month of February was chosen to illustrate the decadal variability but the results would have been basically the same if the December or January averages were used. It is apparent that the averages for the perennial ice cover are considerably more extensive than the corresponding averages for the multiyear ice cover. This is consistent with the results of Zwally and Gloersen (2008). This is mainly because of the 30\% threshold used in the multiyear ice algorithm that excludes data elements with low multiyear ice concentrations and a large fraction of the second-year ice cover. The perennial ice concentration maps also include a small fraction of new and first-year ice that may have formed because of early freeze up in some high-latitude areas during the end of the summer period (Zwally and Gloersen 2008).

The first set of images shows that the interdecadal declines in the perennial ice cover occurred mainly near the marginal ice zone. The changes in the perennial ice cover appear to be a systematic retreat that is especially large in the Beaufort, Siberian, Laptev, and Barents Seas. The averages for the third decade show significantly larger areas of ice-free water, especially at the Beaufort Sea and the Siberian-Laptev Seas regions, indicating a much larger ice decline from the second to the third decades compared to that of the first two. The trends in the perennial ice cover, as presented in Fig. 6d, show the locations that have been most vulnerable to change. The color-coded map represents the results from linear regressions using monthly 

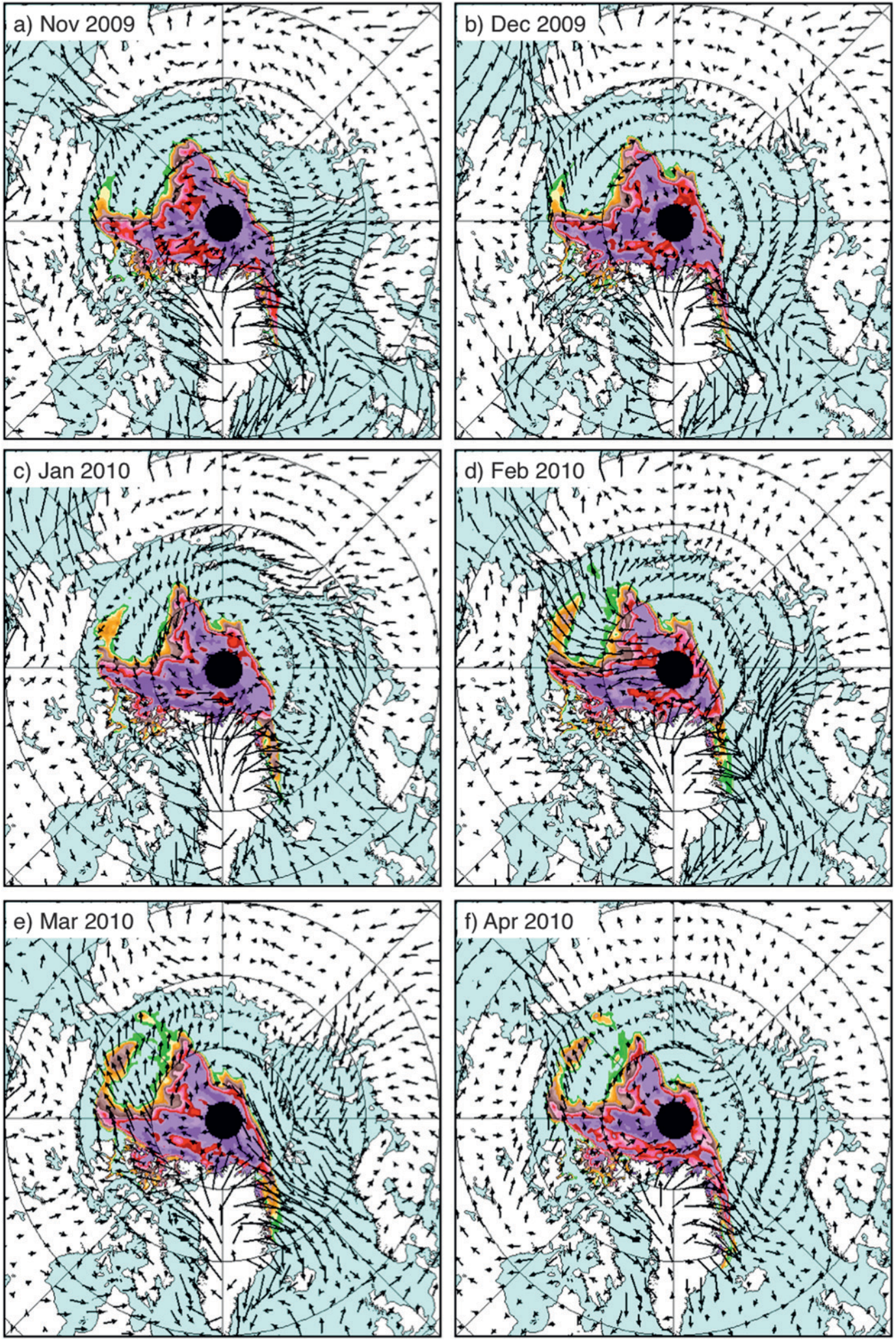
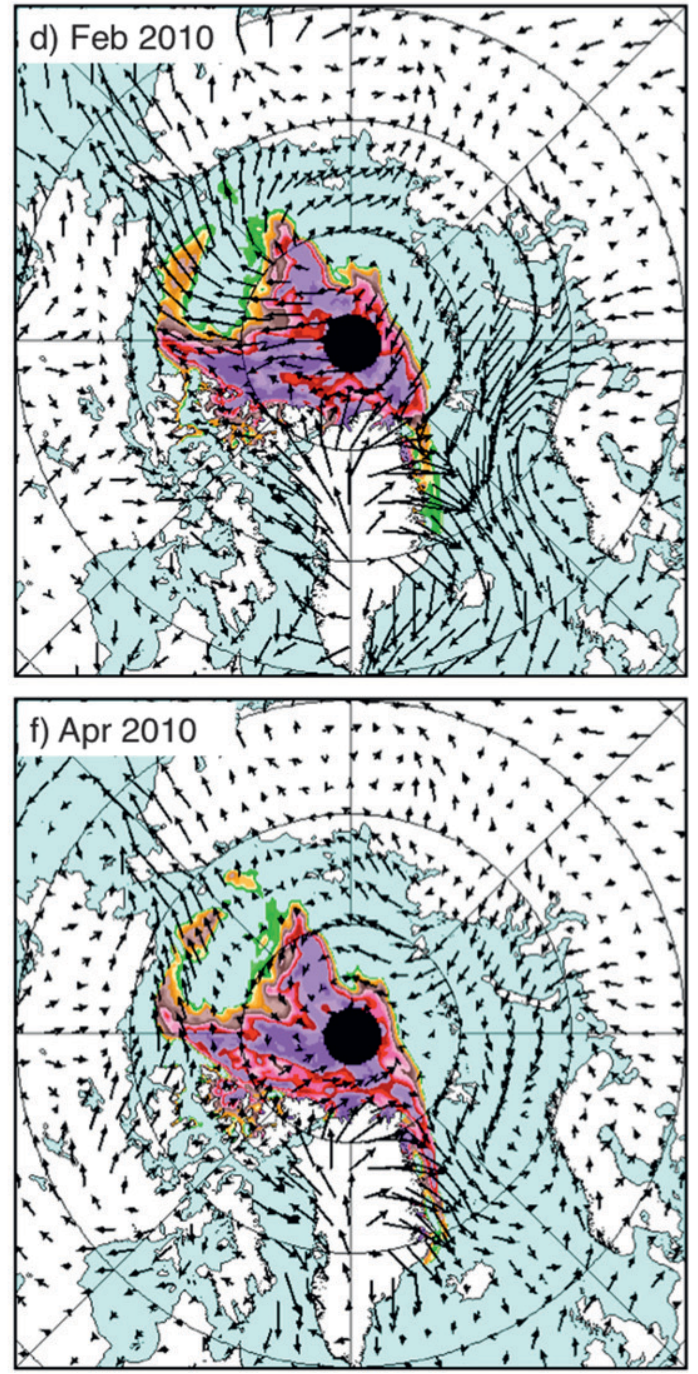

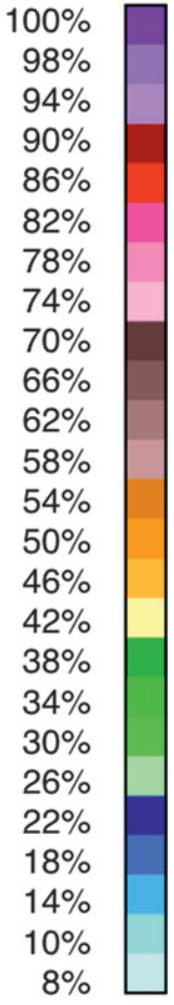

Multiyear Ice Concentration

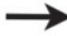

$10 \mathrm{~m} / \mathrm{s}$

FIG. 4. Color-coded multiyear ice concentration maps for each month from November 2009 to April 2010 as inferred from AMSR-E data and the corresponding monthly average wind vectors (from NCEP-NCAR reanalysis data). 

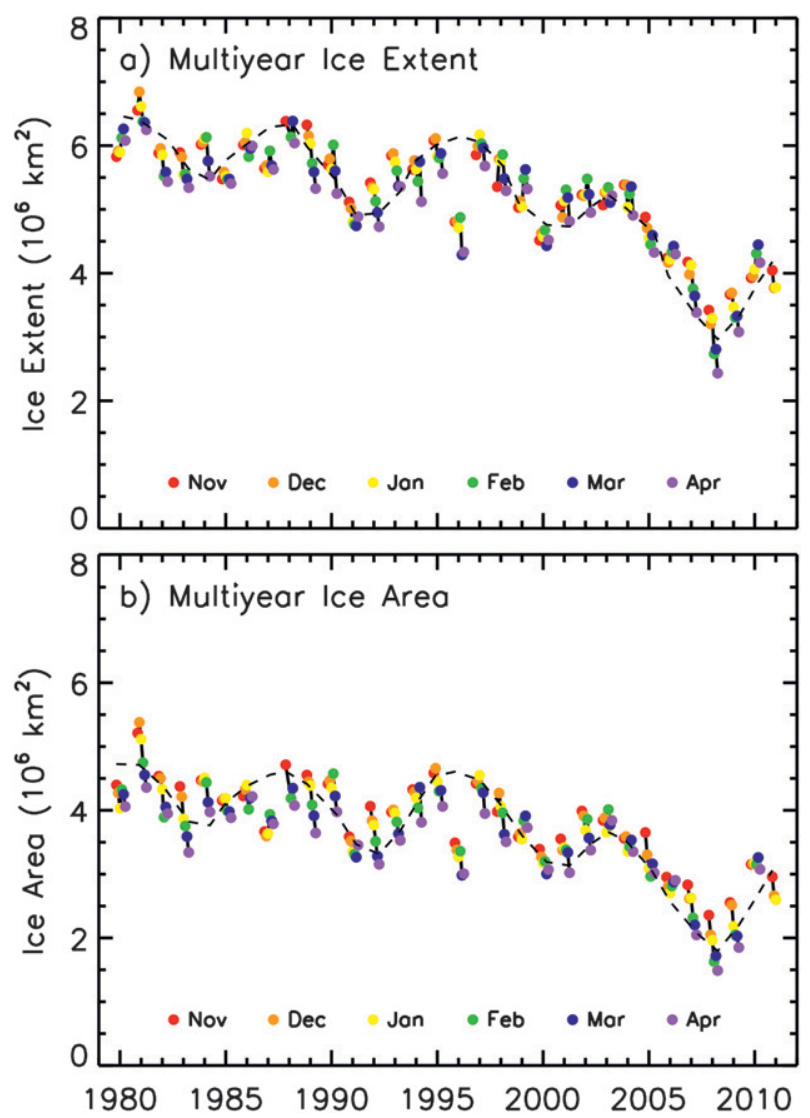

FIG. 5. Multiyear (a) ice extent and (b) ice area for the dry months of November-April from 1978 to 2010. The different months are color coded. The dash lines are hand drawn to illustrate that there may be a periodicity in the pattern of about 8-9 yr.

ice concentration anomalies in each data element (pixel) from 1979 to 2009. It is apparent that the declines are largest in the western regions that include the Beaufort, Chukchi, and Siberian Seas. The trends are more moderate in the eastern region.

The decadal changes in the multiyear ice cover, as depicted in Fig. 6, are considerably greater than those of the perennial ice not just in extent but in shape as well. The averages for the first and third decades show a sharp corner protruding in the Siberian Sea, while the averages for the second decade looks more circular with no distinct patterns at the edges. Such decadal changes in pattern may be associated with interdecadal changes in the circulation pattern of the sea ice, as reported by Proshutinsky and Johnson (1997). The decadal changes in the multiyear ice cover are also shown to be much larger from the second to the third decade than from the first to the second, especially in the Beaufort Sea and north of the Kara and Barents Seas. The trends in the multiyear ice cover as shown in Fig. 6h show that changes were not confined to the marginal ice regions but occurred all the way to the interior regions. The appearance of an approximately linear pattern of negative trend (in red) from the Siberian Sea to Fram Strait in the trend map is conspicuous, especially since the linear feature overlaps with the transpolar drift region. This suggests that the ice cover that is advected from the Arctic through Fram Strait has a lower concentration of multiyear ice in recent years that in earlier years. Such a phenomenon needs to be taken into consideration when quantitative estimates of the multiyear ice area exported from the Arctic are being made.

\section{b. Trends in multiyear and perennial ice cover}

The yearly extent and area of the perennial and multiyear ice cover in the central Arctic (i.e., excluding the Greenland Sea multiyear ice cover) are presented in Fig. 7. The perennial ice extent and area are derived from data during the summer minimum, which occurs usually in September, while the corresponding values for multiyear ice cover are averages of the monthly values in the winter period (i.e., December-February). The plots show large but similar interannual variability for both the perennial and multiyear ice cover. Note that the extent of the perennial ice cover, which was as high as about $8 \times 10^{6} \mathrm{~km}^{2}$ in the early 1980 s, went down in value to as low as about $4 \times 10^{6} \mathrm{~km}^{2}$ in the latter part of the 2000s. Similarly, the multiyear ice extent went down from about $6.2 \times 10^{6} \mathrm{~km}^{2}$ in the 1980 s to about $2.8 \times$ $10^{6} \mathrm{~km}^{2}$ in the late 2000s. Using linear regression analysis, the trends of the perennial ice extent and ice area were estimated to be strongly negative at $-12.2 \%$ and $-13.5 \% \pm 1.6 \%$ decade $^{-1}$, respectively, for the period from 1979 to 2010 . These values are considerably higher than the $9 \%$ decade $^{-1}$ reported by Comiso (2002) for an earlier time period (i.e., 1979-2000). The trends in the multiyear ice extent and area turned out to be an even more negative rate at $-15.6 \%$ and $-17.5 \% \pm 2.4 \%$ decade $^{-1}$, respectively, for the period from 1981 to 2011. The higher negative trend in ice area compared to that of the ice extent indicates that the concentration of multiyear ice in the perennial ice region has been declining as well. The rate of decline in the extent and area of the multiyear ice cover is unusually high but is consistent with the observed decline of old ice types as inferred from an analysis of ice drift and ice age data by Maslanik et al. (2007) suggesting that the thickest and oldest ice type in the Arctic has been declining significantly. The higher negative trend for the thicker multiyear ice area than that for the perennial ice area also implies that the average thickness of the ice cover, and hence the ice volume, have also been declining. These results are consistent with the reported decline of ice thickness as observed from submarine data (Rothrock et al. 1999; Wadhams and Davis 2000) and satellite data (Kwok and Rothrock 2009). 

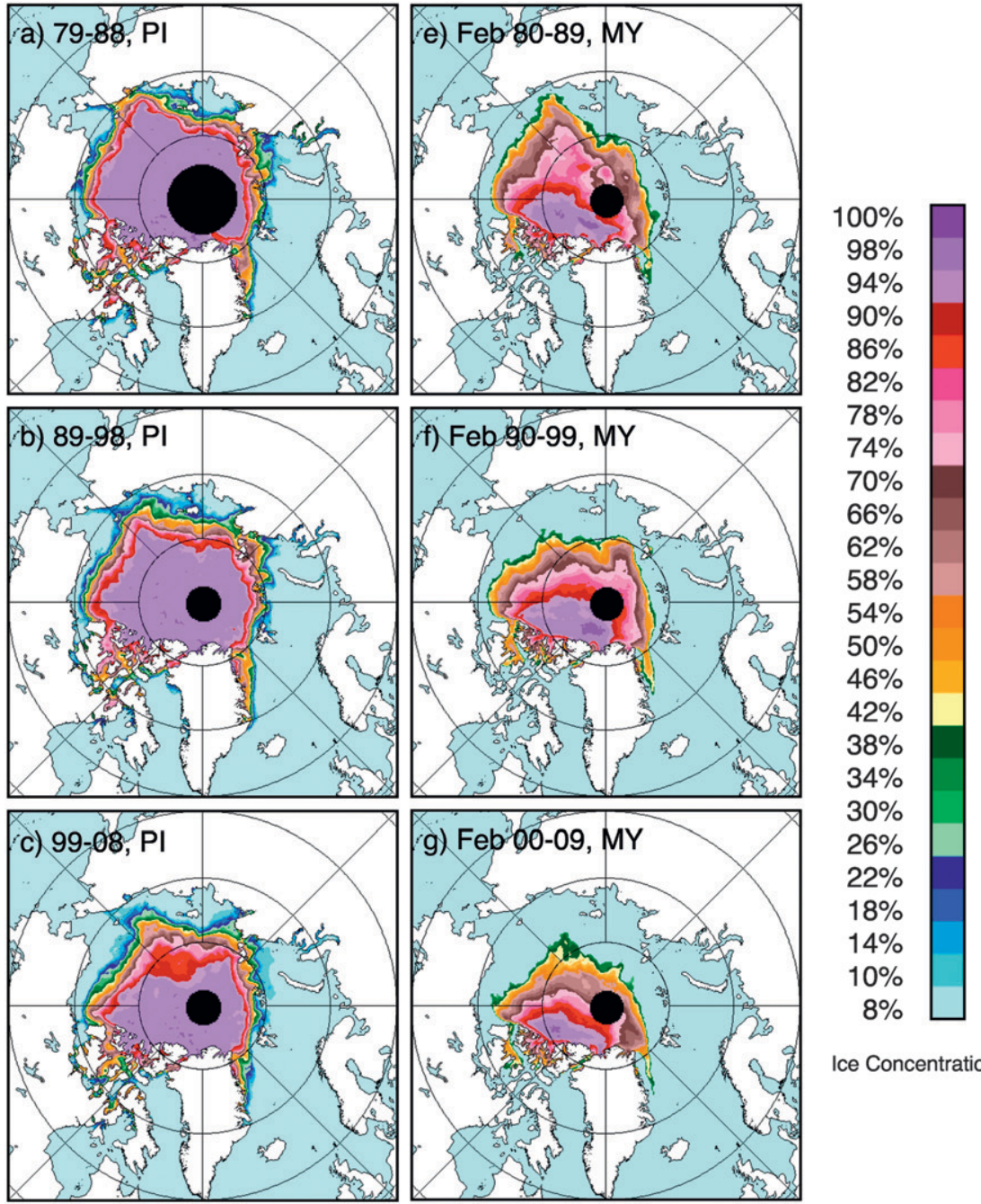

Ice Concentration
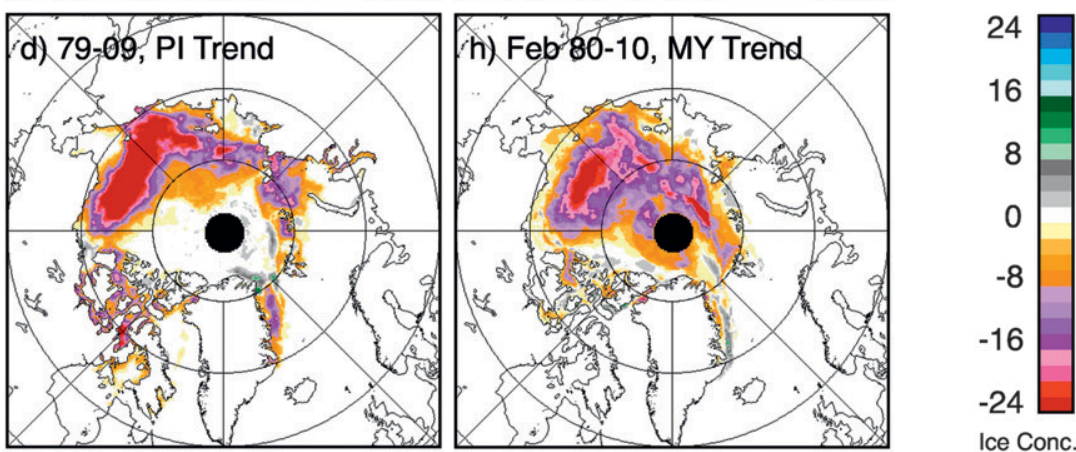

Ice Conc./dec

FIG. 6. The 10-yr averages of the (a)-(c) perennial and (e)-(g) multiyear ice cover and trends in (d) the perennial ice from 1979 to 2009 and (h) the multiyear ice from 1980 to 2010. The monthly February data are used to represent multiyear ice for the winter period. The use of other winter months would not change the images significantly.

Errors in the retrieval of perennial and multiyear ice are difficult to establish because of the lack of in situ data that are spatially extensive enough to be compared with satellite data. Good consistency of the ice concentration and the location of the ice edge between the PM values and those from Moderate Resolution Imaging Spectroradiometer (MODIS) 250-m data in the summer has been observed (Comiso and Nishio 2008; Comiso and 

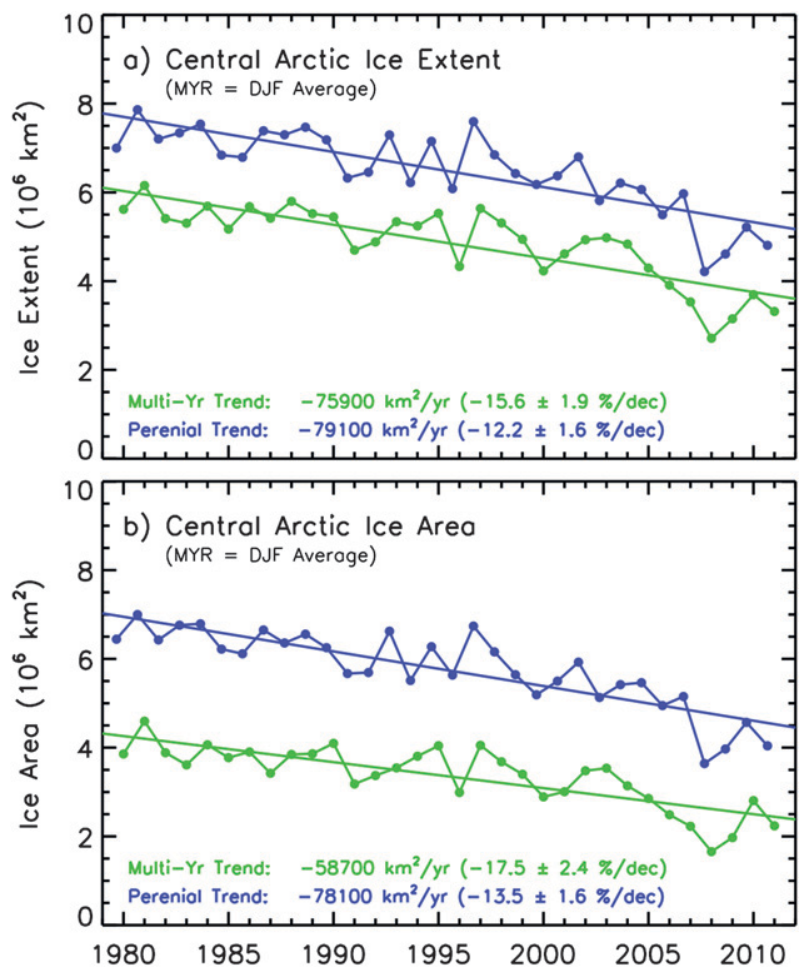

FIG. 7. Perennial and multiyear (a) ice extent and (b) ice area for each year from 1979 to 2010. The values plotted for multiyear ice are averages of December-February values. The last data point for multiyear ice is for the month of November only. The multiyear ice cover in the Greenland Sea was excluded in the estimates.

Parkinson 2008) using either the National Aeronautics and Space Administration (NASA) bootstrap or the NASA Team 2 (NT2) algorithms. The perennial ice extents and areas that are derived directly from ice concentration data using the bootstrap algorithm are thus expected to be credible but they are significantly higher than those presented by Zwally and Gloersen (2008), which made use of the NASA Team 1 (NT1) algorithm. NT1 generally provides lower ice concentration values because of a different algorithm technique, a different set of tie points, and different procedures for addressing the meltponding issue that tends to bias the summer ice concentration values. The Synthetic Aperture Radar (SAR) data provide a relatively accurate assessment of multiyear ice in the winter and have been used to show that QuikSCAT data provide consistent multiyear ice (Kwok 2004). We have compared retrieved multiyear ice data from QuikSCAT with corresponding PM data presented in Fig. 7 for the period 2000-10 and the results show general agreement and good consistency in their patterns and spatial distribution. Quantitatively, the ice cover areas derived from QuikSCAT are slightly higher than the ice area derived from PM but lower than the ice extent derived from the PM. However, the interannual variability and trends are similar and the biases are likely caused by differences in the thresholds for multiyear ice cover. The QuikSCAT and PM (see Fig. 7) multiyear ice areas are both significantly higher than those presented in Zwally and Gloersen (2008). Figure 7 also show good consistency, as expected, of the temporal variability of the perennial ice extents and areas with those of multiyear ice extents and areas but this is not the case with the results reported by Zwally and Gloersen (2008).

A key source of error for the multiyear ice retrieval is the use of a tie point in the algorithm for multiyear ice concentration as discussed earlier. The tie point represents basically the average emissivity of multiyear ice for the particular time period. Errors associated with changes in emissivity from one month to another and from one year to another are minimized through the introduction of the dynamic tie point, as indicated earlier. However, because of the lack of in situ data to establish the true average emissivity, there can a bias associated with the retrieved data. A sensitivity study has been performed to establish the effects of using different tie-point locations with respect to the frequency histogram. Assuming a $\pm 10 \%$ error in the choice of the multiyear (MY) tie point, we estimate a bias of only about $\pm 0.07 \times 10^{6} \mathrm{~km}^{2}$ for ice extent and $\pm 0.2 \times 10^{6} \mathrm{~km}^{2}$ for ice area. Moreover, the trends changed only from -15.6 to $-15.2 \times 10^{6} \mathrm{~km}^{2}$ for multiyear ice extent and from -17.5 to $-17.4 \times 10^{6} \mathrm{~km}^{2}$ for multiyear ice area.

\section{Connections with surface temperature, sea level pressure, and winds}

\section{a. Surface temperature}

Decadal averages of Arctic surface temperature as derived from Advanced Very High Resolution Radiometer (AVHRR) data using the technique discussed in Comiso (2010) are presented in Figs. 8a-c for the first, second, and third decades, respectively. The decadal averages show that, at least for the last three decades, the spatial distribution and patterns of the isotherms and the location of extremely cold and warm areas are basically the same. Significant decadal changes, however, occurred, as revealed by the differences between the first and second decades (Fig. 8d) as well as those for the second and third decades (Fig. 8e). It is also shown that although the differences are dominantly positive (i.e., indicating warming) especially in North America, there are regions where some cooling has been concurrently going on. For example, in Fig. 8d, cooling is apparent mainly in the western part of Russia and the Barents Sea region. Some cooling also occurred in parts of Greenland, North America, and the Bering Sea. In Fig. 8e, cooling was more widespread in Russia, becoming more expansive in the western region, 

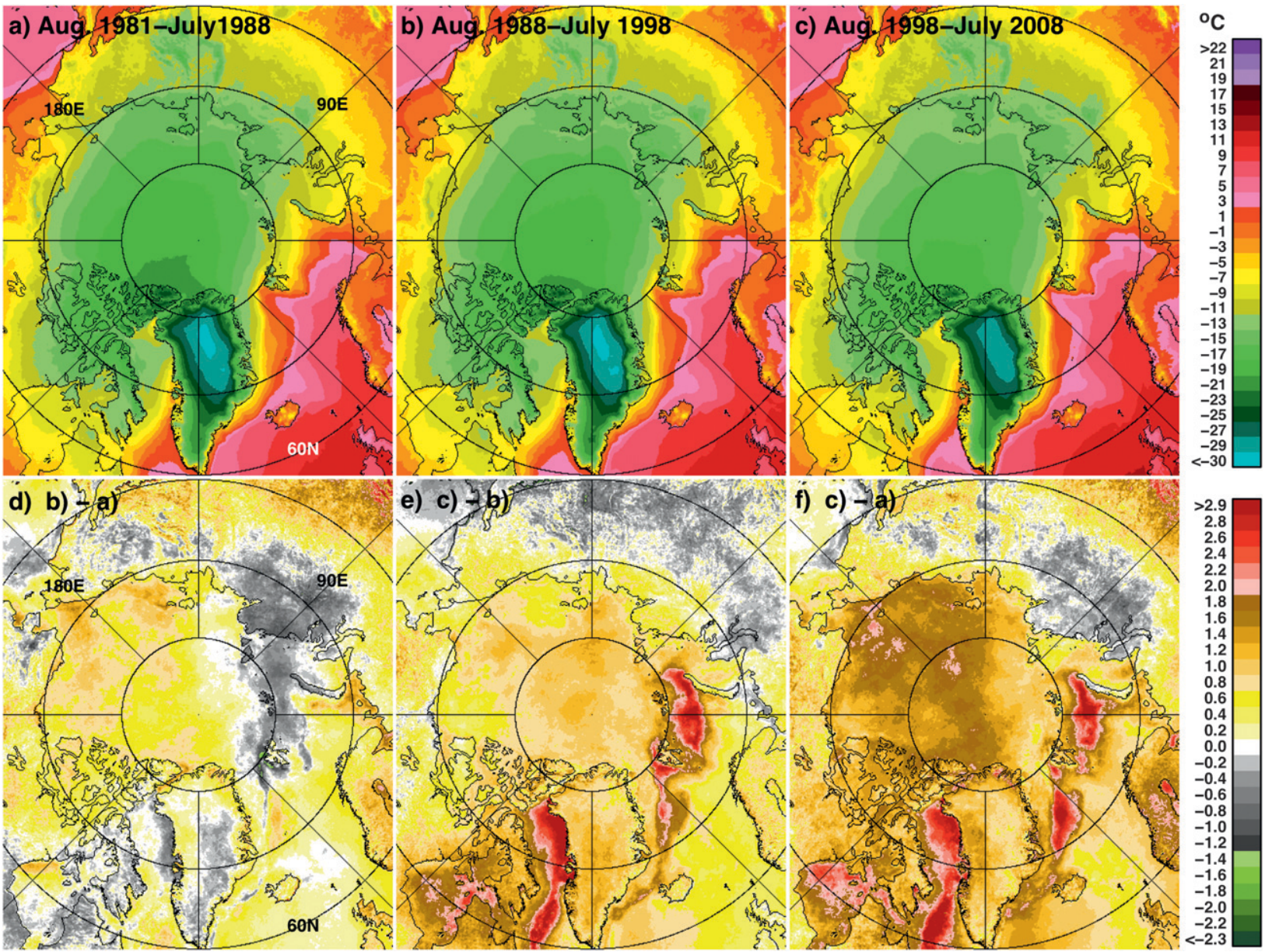

FIG. 8. Multiyear averages of surface temperature in the Arctic region for the periods (a) August 1981-July 1989, (b) August 1989-July 1999, and (c) August 1999-July 2009 and difference maps for (d) the map in (b) minus the map in (a),(e) the map in (c) minus the map in (b), and (f) the map in (c) minus the map in (a).

including the Sea of Okhotsk and the Bering Sea. The anomalies in the central Arctic region, North America, and Greenland, however, became more dominantly positive with extreme values occurring in the Baffin Bay and Barents Sea, reflecting sea ice retreats in these regions during the period. The difference map between the first and the third decades (Fig. 8f) shows higher positive values than for those shown in Figs. 8d,e, indicating that the third decade was considerably warmer than the first decade and significantly warmer than the second decade. The difference map indicates that some cooling is apparent in parts of eastern Russia and the Bering Sea. On the other hand, the extremely high positive values have expanded to include the Greenland Sea and Hudson Bay, which are areas where the sea ice cover has declined significantly during the last three decades.

A more quantitative evaluation of the interannual variability of surface temperature is presented in the plots of temperature anomalies and for different regions of the Arctic at $>60^{\circ} \mathrm{N}$ (Fig. 9). The anomalies show large interannual fluctuations and even some periodic but not consistent patterns in some regions. The trends from linear regression analyses are consistently positive but vary significantly in value from one region to another with the trends being $0.44^{\circ} \pm 0.06^{\circ}, 0.82^{\circ} \pm 0.11^{\circ}$, $0.16^{\circ} \pm 0.08^{\circ}$, and $0.54^{\circ} \pm 0.09^{\circ} \mathrm{C}$ decade $^{-1}$, for sea ice, Greenland, Eurasia, and North America, respectively. The yearly averages are also shown in Fig. 9, and it appears that the trends are basically the same as those from the monthly anomalies.

For direct comparison of sea ice with surface temperature, monthly anomalies of the sea ice area and surface temperature over sea ice in some sectors of the Arctic (as described in Parkinson et al. 1999) are presented in Fig. 10. The sectors are those in the central Arctic and adjacent seas (i.e., Kara-Barents Seas, Okhotsk-Japan Seas, Bering Sea, and Greenland Sea). The trend in the sea ice cover is generally negative in regions where the trends in surface 


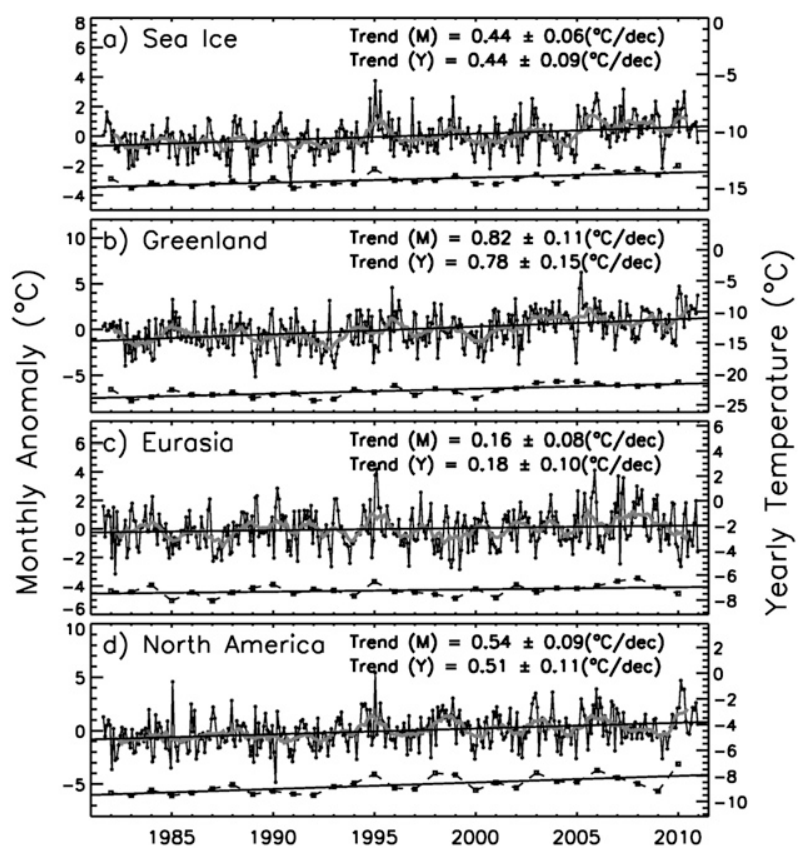

FIG. 9. Monthly surface temperature anomalies and yearly averages at $>60^{\circ} \mathrm{N}$ over (a) sea ice, (b) Greenland, (c) Eurasia, and (d) North America and estimated trends.

temperatures are positive for all sectors except in the Bering Sea sector, which is the only sector where the trend in the sea ice cover is positive at $4.5 \% \pm 1.6 \%$ decade $^{-1}$. In this case, although there are areas where cooling has been observed (i.e., Fig. 8), the net trend in surface temperature is slightly positive at $0.15^{\circ} \pm 0.05^{\circ} \mathrm{C}$ decade $^{-1}$. In the Kara-Barents, Okhotsk, and the Greenland Seas, the trends in the sea ice extent are $-9.8 \% \pm 0.7 \%$, $-9.6 \% \pm 0.17 \%$, and $-8.0 \% \pm 0.8 \%$ decade $^{-1}$, respectively, while the corresponding trends in surface temperatures are $0.94^{\circ} \pm 0.09^{\circ}, 0.41^{\circ} \pm 0.05^{\circ}$, and $0.77^{\circ} \pm 0.03^{\circ} \mathrm{C}$ decade $^{-1}$. In these regions, the trends in surface temperature are highly consistent with the trends in the sea ice cover. In the central Arctic, the trend in ice extent is $-2.0 \% \pm 0.2 \%$ decade $^{-1}$ while that of surface temperature is $1.1^{\circ} \pm 0.10^{\circ} \mathrm{C}$ decade $^{-1}$. Despite the relatively high trend in surface temperature, the negative trend in ice area is relatively weak in this case, because the ice cover is near $100 \%$ for most of the year and the ice anomaly in the region for each year is near zero.

Scatterplots of sea ice area versus surface temperature for each of the five sectors (not shown) show negative linear patterns indicating strong correlation between the two variables. The results of regression analyses show that the data in the Bering Sea Sector actually have the highest correlation, with a correlation coefficient of -0.796 , while those of the Kara/Barents, Greenland, and Okhotsk Seas following closely at $-0.784,-0.754$, and -0.732 , respectively. The high correlation between the two variables is a manifestation of the strong connection of surface temperature with that of the sea ice cover. In the central Arctic region, the correlation coefficient is significant at -0.641 but relatively lower than the other three, in part because for most of the year, the sea ice area is almost constant and near maximum values while the surface temperature fluctuates significantly. The surface temperature data, however, show warming anomalies, not just in the seasonal ice regions but also in the perennial ice region and the adjacent land and sea areas. The warming is in part due to atmospheric warming that is associated with the retreat of the sea ice cover as described by Screen and Simmonds (2010). The general warming in these areas would increase the length of the melt season as reported by Markus et al. (2009) and shorten the length of the ice season that in turn causes the ice cover to be generally thinner than normal.

For completeness, changes in SST were evaluated using AVHRR data from 1981 to 2010 at high-latitude regions (i.e., $>60^{\circ} \mathrm{N}$ ) in the Arctic and for the eastern (Atlantic side) and western (Pacific Side) regions. With a few exceptions, the yearly fluctuations are usually less than $1^{\circ} \mathrm{C}$. The trend for the entire Arctic region was estimated to be $0.24^{\circ} \pm 0.02^{\circ} \mathrm{C}$ decade $^{-1}$ while those for the eastern and western regions were $0.22^{\circ} \pm 0.03^{\circ}$ and $0.25^{\circ} \pm 0.02^{\circ} \mathrm{C}$ decade $^{-1}$, respectively. The relatively high trends in SST suggest a significant influence of ice-albedo feedback associated with the rapid decline in the summer ice cover during the last three decades. This is consistent with previous studies (Perovich et al. 2008; Lindsay et al. 2009). The AVHRR data also show that the SST in the western Arctic was abnormally high in 2007 and consistent with observations using the passive microwave data as reported by Shibata et al. (2010).

The main source of error in the retrieval of surface temperature from AVHRR data is the masking of clouds, which becomes even more complicated in the polar regions because of the difficulty in discriminating the albedo of iceand snow-covered areas from those of clouds. Among the techniques utilized is the daily differencing technique, as described by Comiso (2003), in which clouds are assumed to move from one day to the next and the difference in the daily data provides cloud information. Comparative analysis of retrieved AVHRR monthly surface temperatures with corresponding values from meteorological stations and automatic weather stations (AWSs) yielded RMS errors of between $2.5^{\circ}$ and $3^{\circ} \mathrm{C}$. However, some of the meteorological and AWS data are known to have erroneous values because of snow cover effects or malfunctions of the thermal sensors (e.g., thermistors). When the average values of all the station data for each month are compared with those of AVHRR data, the results are encouraging 
Surface Temperature Anomaly
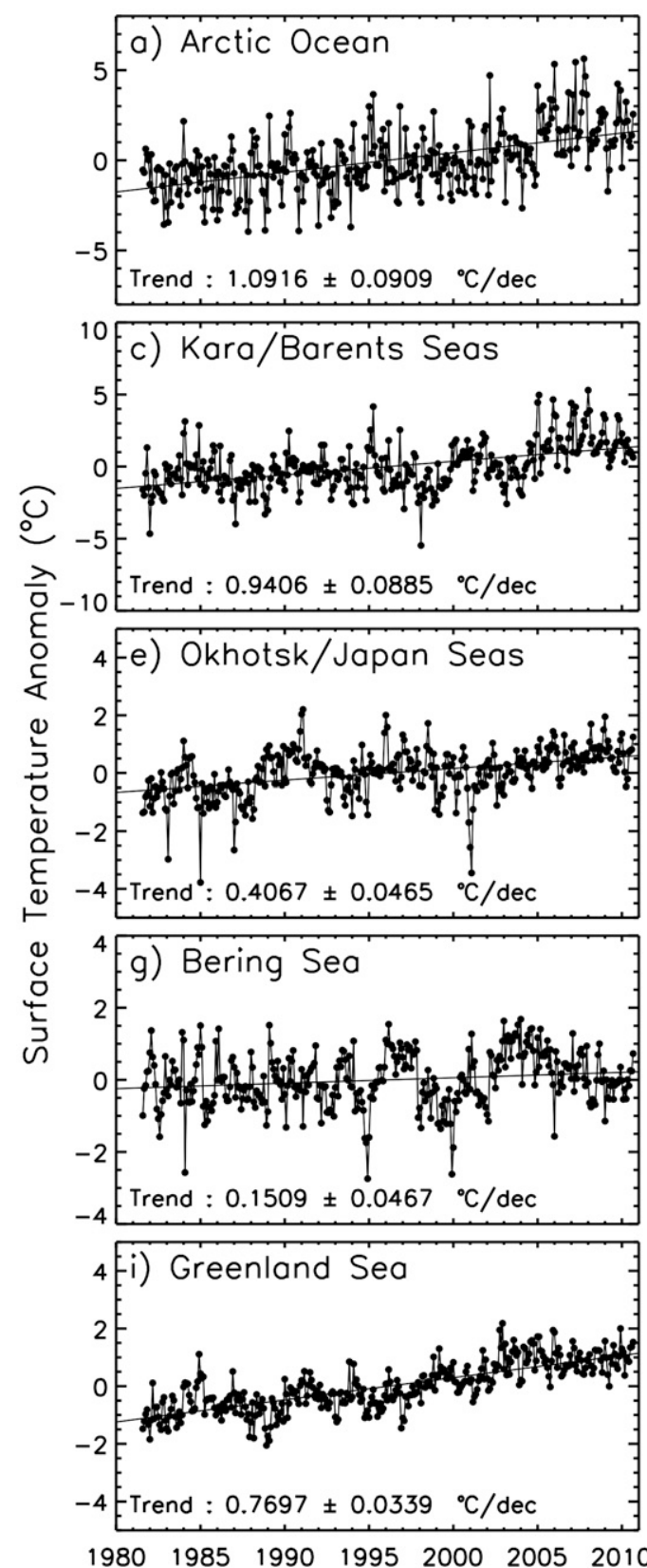

Sea Ice Extent Anomaly
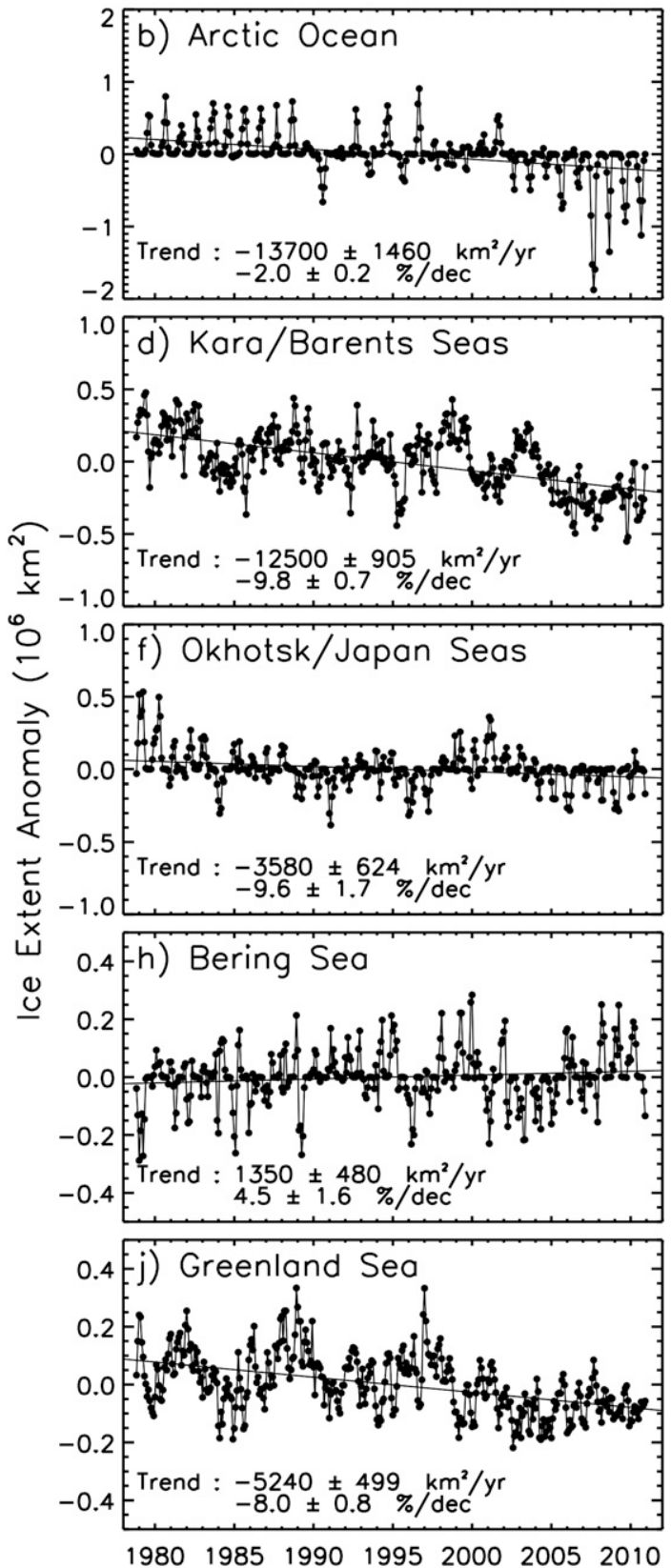

FIG. 10. Monthly surface temperature anomalies in the (a) Arctic Ocean, (c) Kara-Barents Sea, (e) OkhotskJapan Seas, (g) Bering Sea, and (i) Greenland Sea; ice area anomalies in the (b) Arctic Ocean, (d) Kara-Barents Sea, (f) Okhotsk-Japan Seas, (h) Bering Sea, and (j) Greenland Sea.

and indicate that the AVHRR data can have RMS errors of $0.8^{\circ} \mathrm{C}$ or lower.

\section{b. Sea level pressure and winds}

To assess how changes in atmospheric wind patterns and sea level pressure (SLP) alter the distribution and influence the interannual changes in the sea ice cover, we make use of the National Centers for Environmental Prediction-National Center for Atmospheric Research (NCEP-NCAR) reanalysis dataset as discussed by Kalnay et al. (1996). Decadal averages of SLP and winds for a winter month (February) are presented in Fig. 11. The spatial patterns of the SLP distributions for the three decades are shown to be similar with the highs generally 

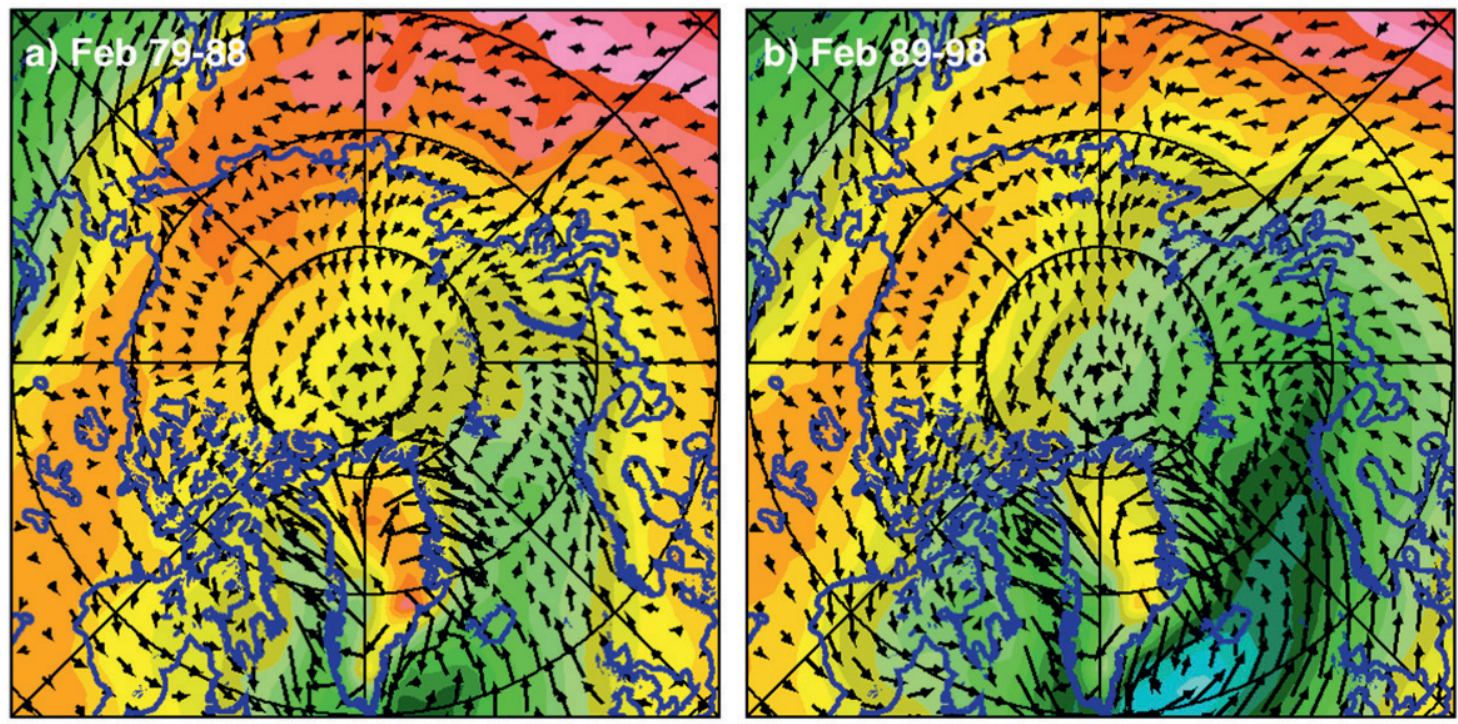

1041
1037
1033
1029
1025
1021
1017
1013
1009
1005
1001
997
993
989
985
981
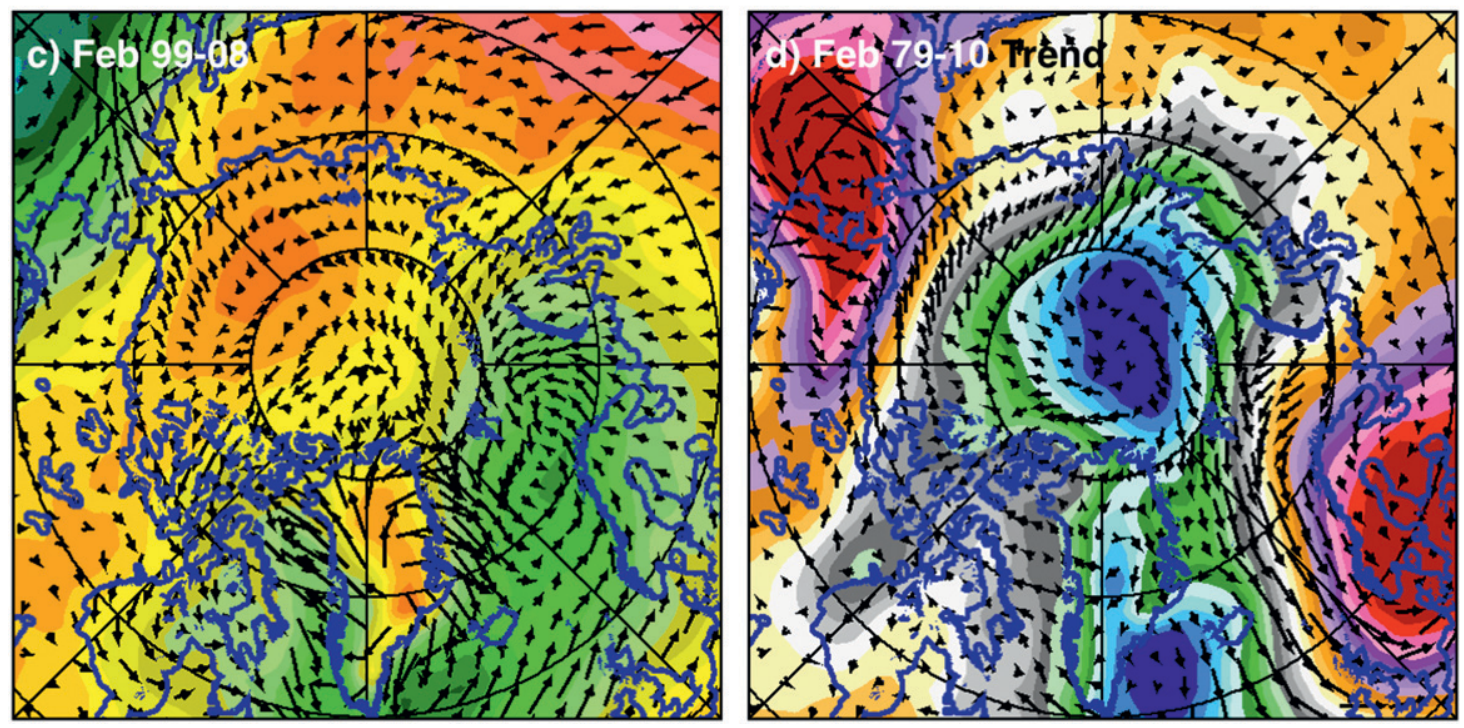

$\mathrm{SLP}, \mathrm{mb}$

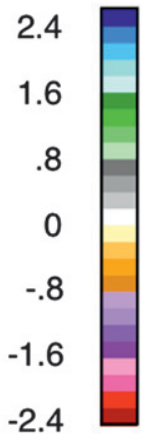

$\mathrm{mb} / \mathrm{dec}$

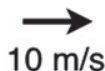

FIG. 11. Multiyear averages of monthly SLP and winds in February for (a) 1979-88, (b) 1989-98, and (c) 1999-2008, and (d) trends in SLP and winds from 1979 to 2009 .

in the central Arctic region, Russia, North America, and Greenland, and the lows in the North Atlantic and North Pacific regions. From the first to the second decade, the lows in the North Atlantic expanded and moved to the east. From the second to the third decade, the North Atlantic lows retreated to the west though not as far back as in the first decade. Meanwhile, the lows in the North Pacific deepened from the first to the second decade and also from the second to the third decade. The results of our trend analysis of the pressure fields are presented in Fig. 11d and show that the highs were further enhanced in the central Arctic while the lows deepened in both the North Pacific and North Atlantic. The wind patterns show subtle changes from one decade to another but, overall, the trend in the central Arctic is a net increase in northerly winds. This would cause sea ice near the poles to be advected to the south, primarily to the southern Beaufort, Siberian, and Laptev Seas, where they are likely to melt in the summer.

Periodic changes from the typical anticyclonic to an cyclonic wind circulation pattern have been suggested in various studies (i.e., Proshutinsky and Johnson 1997; Asplin et al. 2009) but during the satellite era, starting in 1978, such periodicity has not been consistently observed. The data shown in Fig. 11 depict some (but not dramatic) changes in wind direction from one decade to another. The decadal averaging, however, may not provide information 


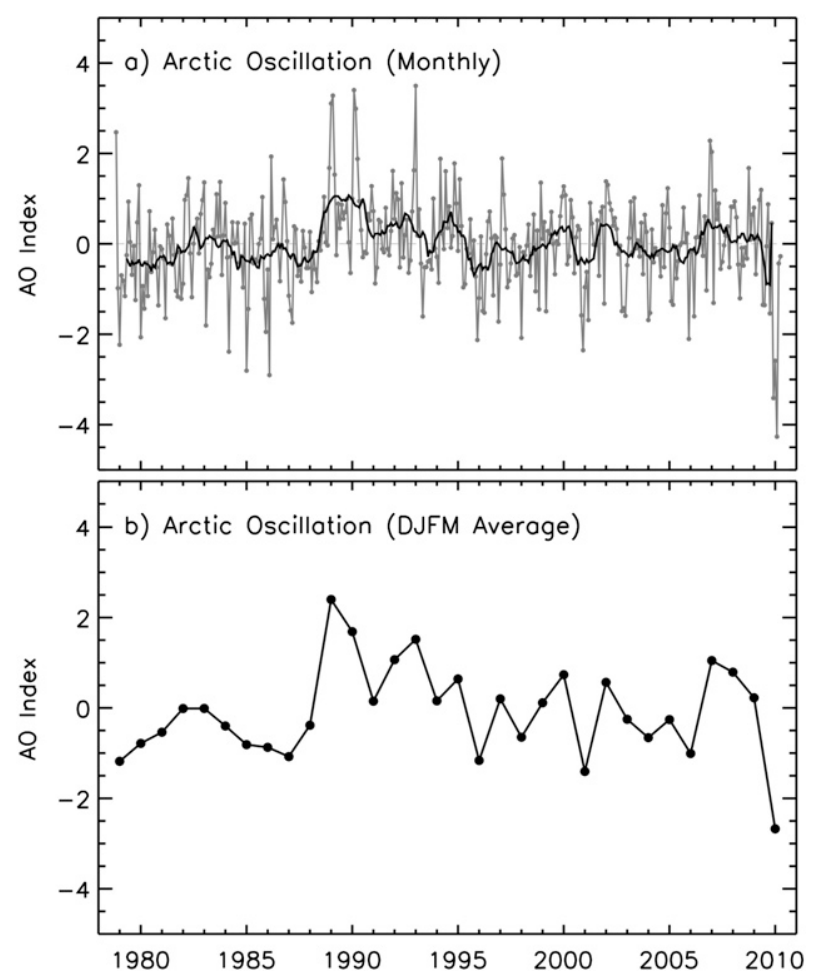

FIG. 12. The AO indices for (a) each month from November 1978 to December 2010 and (b) each winter (DJFM) from 1979 to 2010.

about the actual changes that may occur at shorter time periods. It is important to monitor the atmospheric circulation patterns since some wind patterns are favorable to the advection of multiyear or thick ice through Fram Strait and eventually to the Atlantic Ocean where they melt. Such events could cause significant interannual changes in the extent of the multiyear ice cover.

It has been postulated by Thompson and Wallace (1998) that the atmospheric circulation pattern in the Arctic is controlled by the Arctic Oscillation (AO). The AO has been quantified through the use of AO indices, which are the differences in the SLP of an annular region in the upper-midlatitude region $\left(>40^{\circ} \mathrm{N}\right)$ in the Northern Hemisphere and the central Arctic region. Using data provided by the National Oceanic and Atmospheric Administration's (NOAA) Climate Prediction Center, monthly AO indices from November 1978 to December 2010 are presented in Fig. 12a, while yearly averages of AO indices for each winter (DJFM) from 1979 to 2010 are presented in Fig. 12b. Negative AO indices (e.g., 1979-88) have been associated with relatively high extents in the sea ice cover while positive indices (e.g., 1989-95) have been associated with relatively low extents in the ice cover (Rigor et al. 2002). However, since 1996, the indices have not been consistent and would go from negative to positive and back to negative from one year to another.
The AO was regarded as being basically neutral during the last decade (Overland and Wang 2005) and led others to postulate a radical shift in the atmospheric circulation (X. Zhang et al. 2008). During this time period, the sea ice cover continued to decline after a peak value in September 1996 (see Fig. 1a). The high variability of the ice extents in 2007, 2008, 2009, and 2010 and the anomalously low values in September during each of these years are also shown to be unprecedented. The AO indices were positive (but not as high as in 1989 and 1990) during this period until they dropped down to record low values in 2010, as has also been reported by Stroeve et al. (2011). The impacts of such a drop in the AO index on the sea ice cover would be interesting to know but are not clearly manifested in the current ice data.

The results of a correlation analysis of the data show a relatively weak relationship between the sea ice cover and AO indices. Using monthly data in winter, autumn, and spring (October-April) from 1978 to 2010, regression analysis yielded correlation coefficients for $\mathrm{AO}$ versus sea ice extent and $\mathrm{AO}$ versus sea ice area of 0.021 and 0.014 , respectively. The relationship is even weaker when the yearly winter $\mathrm{AO}$ indices were regressed versus multiyear extents and multiyear ice areas, since they yielded correlation coefficients of -0.0026 and 0.0006 , respectively. However, this does not mean that the AO does not affect the sea ice cover. The general location and distribution of the perennial ice and the multiyear ice cover are affected by the atmospheric circulation, which is basically controlled by the AO. During some years, the perennial ice cover is advected to the west causing the occurrence of only a limited area of open water in the Beaufort Sea region in summer while during other years the ice is advected to the east causing a large area of open water to occur in the region in summer. The location of the ice edge is thus affected by dynamics that may be associated with the AO and could make a big difference in terms of the rate of melt of sea ice.

\section{Discussion and conclusions}

Satellite observations of the perennial ice cover in the Arctic region have provided some of the most convincing evidence of a rapidly changing Arctic. The updated values for the trends in the extent and area of the perennial ice are $-12.2 \%$ and $-13.5 \%$ decade $^{-1}$, respectively, revealing stronger negative trends than previously reported. The analysis of the thick component of the perennial ice, called multiyear ice, as detected by satellite data in winter, yielded even more rapid rates of $-15.6 \%$ and $-17.5 \%$ decade $^{-1}$ for the multiyear ice extent and ice area, respectively. The higher rate of decline of the multiyear ice than the perennial ice cover is clearly an 
indication that the average thickness of the Arctic ice cover is declining. Such a decline in the thick component of the Arctic ice cover means an even more vulnerable perennial ice cover. It is interesting that the rates of decline are so strongly negative despite slight recoveries in the last $3 \mathrm{yr}$ from the anomalously low values in 2007 and 2008 for perennial and multiyear ice, respectively.

We note that the dramatic decline of the perennial ice cover from 2006 to 2007 is not reflected in the multiyear ice data. The multiyear ice data show a generally monotonic and gradual decline from 2003 to 2008, suggesting that the anomalously low perennial ice cover in 2007 was likely due in part to the melt of a large fraction of the second-year ice in the same summer. This also means that the interannual variability in the perennial ice cover is partly controlled by the interannual variability of the second-year ice cover. It is intriguing that the multiyear ice data show an indication of a periodic cycle of about 8-9 yr, which is similar to the period reported for the Antarctic circumpolar wave. The long-term consistency of the cycle is not known since only $32 \mathrm{yr}$ of data are available, but such cycle could explain the slight recovery for 3 years after 2007. Further studies are needed to better understand the origin, significance, and consistency of this cycle.

Results of regression analyses also indicate that changes in the sea ice cover are strongly correlated with the changes in the surface temperature. The correlation coefficients are however not that high, averaging around 0.75 for the different sectors in the seasonal regions. This indicates that the sea ice cover is controlled by factors other than temperature. Furthermore, the temperature is also controlled by factors other than sea ice, like clouds and the transport of warm and humid air. The correlation is not as high in the central Arctic because the ice concentration in the central Arctic does not change much and is basically close to $100 \%$ except in the summer period, even in periods when the surface temperature is highly fluctuating. Sea surface temperatures in ice-free areas in the Arctic Basin were also unusually high in 2007, when the dramatic decline in the perennial ice cover occurred. This suggests an important role for the ice-albedo feedback in the event and confirms previous studies of the warming effects of the retreat of the sea ice cover (Screen and Simmonds 2010). The results of our comparative analysis of sea ice and multiyear ice area with $\mathrm{AO}$ indicate a much weaker correlation. However, the direct role of AO on the sea ice cover is difficult to quantify by direct correlation analysis. The AO influences the pressure and wind patterns that in turn determine the location of the multiyear ice cover in the winter and summer. Multiyear ice floes located in generally warm ocean areas are likely more vulnerable to melt that those located in colder regions.
Acknowledgments. The author is thankful to R. Gersten of RSI/SESDA-2 and L. Stock of SGT, Inc. for excellent programming and analysis support. This paper also benefitted substantially from the valuable comments and suggestions of two anonymous reviewers. This work was funded by NASA's Cryospheric Sciences Program.

\section{REFERENCES}

Amstrup, S. C., G. M. Durner, I. Stirling, and T. L. McDonald, 2010: Climate change: The prospects for polar bears. Nature, 468, 955-958.

Asplin, M. G., J. V. Lukovich, and D. G. Barber, 2009: Atmospheric forcing of the Beaufort Sea ice gyre: Surface pressure climatology and sea ice motion. J. Geophys. Res., 114, C00A06, doi:10.1029/2008JC005127.

Comiso, J. C., 2002: A rapidly declining Arctic perennial ice cover. Geophys. Res. Lett., 29, 1956, doi:10.1029/2002GL015650.

_ 2003: Warming trends in the Arctic from clear sky satellite observations. J. Climate, 16, 3498-3510.

_ 2006: Impacts of the variability of 2 nd year ice types on the decline of the perennial ice cover. Ann. Glaciol., 44, 375-382. , 2010: Polar Oceans from Space. Springer, 507 pp.

— hanced and compatible AMSR-E, SSM/I, and SMMR data. J. Geophys. Res., 113, C02S07, doi:10.1029/2007JC004257.

_ , and C. L. Parkinson, 2008: Arctic sea ice parameters from AMSR-E using two techniques, and comparisons with sea ice from SSM/I. J. Geophys. Res., 113, C02S05, doi:10.1029/ 2007JC004255.

,,-- R. Gersten, and L. Stock, 2008: Accelerated decline in the Arctic sea ice cover. Geophys. Res. Lett., 35, L01703, doi:10.1029/2007GL031972.

Eppler, D., and Coauthors, 1992: Passive microwave signatures of sea ice. Microwave Remote Sensing of Sea Ice, F. Carsey, Ed., Amer. Geophys. Union, 47-71.

Gloersen, P., W. Campbell, D. Cavalieri, J. C. Comiso, C. L. Parkinson, and H. J. Zwally, 1992: Arctic and Antarctic sea ice, 1978-1987: Satellite passive microwave observations and analysis. NASA Special Publication 511, 290 pp.

Grenfell, T. C., 1992: Surface based passive microwave studies of multiyear ice. J. Geophys. Res., 97, 3485-3501.

Johannessen, O. M., E. V. Shalina, and M. W. Miles, 1999: Satellite evidence for an Arctic sea ice cover in transformation. Science, 286, 1937-1939.

Kalnay, E., and Coauthors, 1996: The NCEP/NCAR 40-Year Reanalysis Project. Bull. Amer. Meteor. Soc., 77, 437-471.

Kay, J. E., T. L'Ecuyer, A. Gettelman, G. Stephens, and C. O'Dell, 2008: The contribution of cloud and radiation anomalies to the 2007 Arctic sea ice extent minimum. Geophys. Res. Lett., 35, L08503, doi:10.1029/2008GL033451.

Kwok, R., 2004: Annual cycles of multiyear sea ice coverage of the Arctic Ocean: 1999-2003. J. Geophys. Res., 109, C11004, doi:10.1029/2003JC002238.

_ 2008: Summer sea ice motion from the $18 \mathrm{GHz}$ channel of AMSR-E and the exchange of sea ice between the Pacific and Atlantic sectors. Geophys. Res. Lett., 35, L03504, doi:10.1029/ 2007GL032692.

— , and D. A. Rothrock, 2009: Decline in Arctic sea ice thickness from submarine and ICESat records: 1958-2008. Geophys. Res. Lett., 36, L15501, doi:10.1029/2009GL039035. 
Lindsay, R. W., J. Zhang, A. Schweiger, M. Steele, and H. Stern, 2009: Arctic sea ice retreat in 2007 follows thinning trend. J. Climate, 22, 165-176.

Liu, J., J. A. Curry, and Y. Hu, 2004: Recent Arctic sea ice variability: Connections to the Arctic Oscillation and the ENSO. Geophys. Res. Lett., 31, L09211, doi:10.1029/2004GL019858.

Markus, T., J. C. Stroeve, and J. Miller, 2009: Recent changes in Arctic sea ice melt onset, freezeup, and melt season length. J. Geophys. Res., 114, C12024, doi:10.1029/2009JC005436.

Maslanik, J. A., C. Fowler, J. Stroeve, S. Drobot, J. Zwally, D. Yi, and W. Emery, 2007: A younger, thinner Arctic ice cover: Increased potential for extensive sea-ice loss. Geophys. Res. Lett., 34, L24501, doi:10.1029/2007GL032043.

Matzler, C., R. O. Ramseier, and E. Svendsen, 1984: Polarization effects in sea ice signatures. IEEE J. Oceanic Eng., 9, 333-338.

Nghiem, S. V., I. G. Rigor, D. K. Perovich, P. Clemente-Colon, J. W. Weatherly, and G. Neumann, 2007: Rapid reduction of Arctic perennial sea ice. Geophys. Res. Lett., 34, L19504, doi:10.1029/2007GL031138.

Ogi, M., I. G. Rigor, M. G. McPhee, and J. M. Wallace, 2008: Summer retreat of Arctic sea ice: Role of summer winds. Geophys. Res. Lett., 35, L24701, doi:10.1029/2008GL035672.

Overland, J. E., and M. Wang, 2005: The Arctic climate paradox: The recent decrease of the Arctic Oscillation. Geophys. Res. Lett., 32, L06701, doi:10.1029/2004GL021752.

Parkinson, C. L., D. J. Cavalieri, P. Gloersen, H. J. Zwally, and J. C. Comiso, 1999: Arctic sea ice extents, areas, and trends, 19781996. J. Geophys. Res., 104 (C9), 20 837-20 856.

Perovich, D. K., J. A. Richter-Menge, K. F. Jones, and B. Light, 2008: Sunlight, water and ice: Extreme Arctic sea ice melt during the summer of 2007. Geophys. Res. Lett., 35, L11501, doi:10.1029/2008GL034007.

Proshutinsky, A. Y., and M. A. Johnson, 1997: Two circulation regimes of the wind-driven Arctic Ocean. J. Geophys. Res., 102, 12 493-12 514.

Rigor, I. G., J. M. Wallace, and R. Colony, 2002: Response of sea ice to the Arctic Oscillation. J. Climate, 15, 2648-2663.

Rothrock, D. A., Y. Yu, and G. Maykut, 1999: Thinning of the Arctic sea-ice cover. Geophys. Res. Lett., 26, 3469-3472.

Schweiger, A. J., J. Zhang, R. W. Lindsay, and M. Steele, 2008: Did unusually sunny skies help drive the record sea ice minimum of 2007? Geophys. Res. Lett., 35, L10503, doi:10.1029/ 2008 GL033463.

Screen, J. A., and I. Simmonds, 2010: The central role of diminishing sea ice in the recent Arctic temperature amplification. Nature, 464, 1334-1337.

Serreze, M. C., 2009: The emergence of surface-based Arctic amplification. Cryosphere, 3, 11-19.
Shibata, A., H. Murakami, and J. Comiso, 2010: Anomalous warming in the Arctic Ocean in the summer of 2007.J. Remote Sens. Soc. Japan, 30, 105-113.

Simmonds, I., C. Burke, and K. Keay, 2008: Arctic climate change as manifest in cyclone behavior. J. Climate, 21, 5777-5796.

Steele, M., W. Ermold, and J. Zhang, 2008: Arctic Ocean surface warming trends over the past 100 years. Geophys. Res. Lett., 35, L02614, doi:10.1029/2007GL031651.

Stroeve, J., M. M. Holland, W. Meier, T. Scambos, and M. C. Serreze, 2007: Arctic sea ice decline: Faster than forecast. Geophys. Res. Lett., 34, L09501, doi:10.1029/2007GL029703.

_ , J. Maslanik, M. C. Serreze, I. Rigor, W. Meier, and C. Fowler, 2011: Sea ice response to an extreme negative phase of the Arctic Oscillation during winter 2009/2010. Geophys. Res. Lett., 38, L02502, doi:10.1029/2010GL045662.

Thompson, D. W., and J. M. Wallace, 1998: The Arctic Oscillation signature in the wintertime geopotential height and temperature fields. Geophys. Res. Lett., 25, 1297-1300.

Tietsche, S., D. Notz, J. H. Jungclaus, and J. Marotzke, 2011: Recovery mechanisms of Arctic summer sea ice. Geophys. Res. Lett., 38, L02707, doi:10.1029/2010GL045698.

Tooma, S. G., R. A. Mennella, J. P. Hollinger, and R. D. Ketchum Jr., 1975: Comparison of sea-ice type identification between airborne dual-frequency passive microwave radiometry and standard laser/infrared techniques. J. Glaciol., 15, 225-239.

Vant, M. R., R. O. Ramseier, and V. Makios, 1978: The complexdielectric constant of sea ice at frequencies in the range 0.140 GHz. J. Appl. Phys., 49, 1234-1280.

Wadhams, P., and N. R. Davis, 2000: Further evidence of ice thinning in the Arctic Ocean. Geophys. Res. Lett., 27, 3973-3975.

Walsh, J. E., and H. J. Zwally, 1990: Multiyear sea ice in the Arctic: Model- and satellite-derived. J. Geophys. Res., 95,11 613-11 628.

Weeks, W. F., and S. Ackley, 1986: The growth, structure and properties of sea ice. The Geophysics of Sea Ice, N. Untersteiner, Ed., Plenum, 9-164.

White, W. B., and R. G. Peterson, 1996: An Antarctic circumpolar wave in surface pressure, wind, temperature and sea ice extent. Nature, 380, 699-702.

Zhang, J., R. Lindsay, M. Steele, and A. Schweiger, 2008: What drove the dramatic retreat of Arctic sea ice during summer 2007? Geophys. Res. Lett., 35, L11505, doi:10.1029/2008GL034005.

Zhang, X., A. Sorteberg, J. Zhang, R. Gerdes, and J. C. Comiso, 2008: Atmospheric circulation signature in recent rapid Arctic climate system change. Geophys. Res. Lett., 35, L22701, doi:10.1029/ 2008 GL035607.

Zwally, H. J., and P. Gloersen, 2008: Arctic sea ice surviving the summer melt: Interannual variability and decreasing trend. J. Glacial., 54, 279-296. 